\title{
Infrared limb emission measurements of aerosol in the troposphere and stratosphere
}

\author{
Sabine Griessbach ${ }^{1}$, Lars Hoffmann ${ }^{1}$, Reinhold Spang ${ }^{2}$, Marc von Hobe ${ }^{2}$, Rolf Müller ${ }^{2}$, and Martin Riese ${ }^{2}$ \\ ${ }^{1}$ Jülich Supercomputing Centre (JSC), Forschungszentrum Jülich GmbH, Jülich, Germany \\ ${ }^{2}$ Institute of Energy and Climate Research (IEK-7), Forschungszentrum Jülich GmbH, Jülich, Germany \\ Correspondence to: Sabine Griessbach (s.griessbach@fz-juelich.de)
}

Received: 27 February 2015 - Published in Atmos. Meas. Tech. Discuss.: 29 April 2015

Revised: 29 June 2016 - Accepted: 28 July 2016 - Published: 7 September 2016

\begin{abstract}
Altitude-resolved aerosol detection in the upper troposphere and lower stratosphere (UTLS) is a challenging task for remote sensing instruments. Infrared limb emission measurements provide vertically resolved global measurements at day- and nighttime in the UTLS. For high-spectralresolution infrared limb instruments we present here a new method to detect aerosol and separate between ice and nonice particles. The method is based on an improved aerosolcloud index that identifies infrared limb emission spectra affected by non-ice aerosol or ice clouds. For the discrimination between non-ice aerosol and ice clouds we employed brightness temperature difference correlations. The discrimination thresholds for this method were derived from radiative transfer simulations (including scattering) and Michelson Interferometer for Passive Atmospheric Sounding (MIPAS)/Envisat measurements obtained in 2011. We demonstrate the value of this approach for observations of volcanic ash and sulfate aerosol originating from the Grímsvötn (Iceland, $64^{\circ} \mathrm{N}$ ), Puyehue-Cordón Caulle (Chile, $40^{\circ} \mathrm{S}$ ), and Nabro (Eritrea, $13^{\circ} \mathrm{N}$ ) eruptions in May and June 2011 by comparing the MIPAS volcanic aerosol detections with Atmospheric Infrared Sounder (AIRS) volcanic ash and $\mathrm{SO}_{2}$ measurements.
\end{abstract}

\section{Introduction}

Aerosol is omnipresent and highly variable in the atmosphere. In the upper troposphere and lower stratosphere (UTLS) a large variety of aerosol particles, comprising sulfate droplets, volcanic ash, mineral dust, wild fire aerosol, organic material, and meteoritic dust, has been found (e.g.
Junge et al., 1961; Mossop, 1964; Prata, 1989a; Murphy et al., 2007; Fromm et al., 2010; Liu et al., 2013; Weigel et al., 2014) (in this paper we do not refer to ice particles or liquid water droplets as aerosol). The stratospheric aerosol is dominated by sulfate aerosol (Junge et al., 1961) and is significantly influenced by volcanic eruptions (e.g. Bauman et al., 2003; Vernier et al., 2011). It has an impact on the radiation budget of the Earth and hence influences climate (Santer et al., 2014; Ridley et al., 2014). The tropospheric background aerosol is also dominated by sulfate aerosol but is disturbed by numerous irregular events, such as volcanic eruptions, mineral dust outbreaks, and fires. In the troposphere some specific aerosol particles serve as condensation nuclei and hence influence cloud formation and precipitation (Fridlind et al., 2004; Yu et al., 2010; Yuan et al., 2011). Aerosol events, such as mineral dust outbreaks from the Sahara fertilising the Amazon forest (Koren et al., 2006) and volcanic ash posing a danger to aircraft (Casadevall, 1994), can be of particular importance for specific questions. Lidar measurements indicate that volcanic aerosol also can be a strongly variable load in the upper troposphere (Di Pierro et al., 2013, Fig. 12).

Aerosol measurements in the stratosphere are available from a variety of sources. In particular, satellite measurements provide global climatologies and time series of stratospheric aerosol (Bauman et al., 2003; Vernier et al., 2011; Kremser et al., 2016). Global long-term observations of upper tropospheric aerosol are rare because they are hampered by the presence of ice clouds (e.g. Kent et al., 2003; Thomason and Vernier, 2013). Hence, many stratospheric aerosol products are only available above $15 \mathrm{~km}$ (Ridley et al., 2014). 
Satellite-based limb instruments, such as the Stratospheric Aerosol and Gas Experiment (SAGE) series (Thomason et al., 1997; Bauman et al., 2003), Optical Spectrograph and InfraRed Imaging System (OSIRIS) (Rieger et al., 2015), and the Halogen Occultation Experiment (HALOE) (Thomason, 2012), have a long-standing history of measuring altituderesolved global time series of stratospheric aerosol. However, the spatial coverage of solar occultation instruments (SAGE, HALOE) is limited. The solar scattering (OSIRIS) measurements are limited to daytime and hence cannot provide measurements at polar night. Also, due to the high sensitivity to low aerosol concentrations of these instruments measuring in the ultraviolet to near-infrared spectral range, their extinction profiles run into saturation for specific aerosol events, such as moderate to major volcanic eruptions (with an volcanic explosivity index of 4; e.g. Sarychev, 2009; Nabro, 2011) and impede measurements below the plume top altitude (Fromm et al., 2014). The $750 \mathrm{~nm}$ extinction coefficient thresholds range from about $3 \times 10^{-3}$ to $0.02 \mathrm{~km}^{-1}$ for OSIRIS and SAGE II respectively (Fromm et al., 2014). Extending these aerosol measurements into the upper troposphere is also challenging because the separation between ice clouds and aerosol is prone to errors for SAGE and HALOE (Kent et al., 2003; Thomason and Vernier, 2013) or is not done for OSIRIS (Fromm et al., 2014).

In contrast, satellite-based infrared (IR) emission measurements provide a global coverage at day- and nighttime during all seasons. Furthermore, IR nadir instruments have a better global and temporal coverage than ultraviolet (UV)/visible (VIS) nadir measurements or occultation measurements. IR nadir measurements have a long-standing history in detecting aerosols and retrieving aerosol composition and microphysics. The aerosol measurements from IR nadir instruments mainly focus on volcanic ash (e.g. Prata, 1989a; Guehenneux et al., 2015), mineral dust (e.g. Peyridieu et al., 2010; Klüser et al., 2011; Klueser et al., 2012; Liu et al., 2013), and smoke (Fromm et al., 2008). There are several methods available to detect aerosol, filter out ice clouds, and classify aerosol types. These methods comprise the split window/reverse absorption technique for volcanic ash (Prata, 1989a, b; Rose et al., 2013), trispectral approaches for volcanic ash and mineral dust (Ackerman et al., 1990; Ackerman, 1997; Guehenneux et al., 2015), and multispectral approaches for hyperspectral instruments (Gangale et al., 2010; Clarisse et al., 2010, 2013). Although the established methods are used for operational data products they are still subject to improvements (Guehenneux et al., 2015). The capability of detecting sulfate aerosol with IR nadir measurements has been demonstrated for band measurements (Baran et al., 1993; Ackerman, 1997) and for hyperspectral instruments (Clarisse et al., 2010; Gangale et al., 2010; Karagulian et al., 2010). Ackerman (1997) found that sulfate droplets with an aerosol optical depth (AOD) larger than 0.01 at $11 \mu \mathrm{m}$ should be detectable from IR nadir measurements. However, a major disadvantage of IR nadir aerosol measurements is the lack of altitude profile information. Another shortcoming is the limited sensitivity towards thin aerosol. IR nadir instruments are not sensitive at low AODs, which are characteristic for polar stratospheric clouds (PSCs) or diluted volcanic sulfate aerosol. Considering UV/VIS solar occultation/scattering measurements and IR nadir measurements together, there is a measurement gap for AODs between 0.02 and 0.1 for sulfate aerosol: for UV/VIS solar occultation/scattering measurements the maximum retrievable AOD is 0.02 (Fromm et al., 2014) and for IR nadir measurements the minimum detectable AOD is 0.01 (Ackerman, 1997), which corresponds to an AOD of about 0.1 in the VIS range for the same scenario (e.g. Bauman et al., 2003).

IR limb emission measurements combine the advantages of occultation and IR nadir measurements. They have better global coverage than occultation measurements and provide altitude information. Limb emission measurements in the IR are highly sensitive towards aerosol, yet only a few studies deal with aerosol detection, aerosol classification, and ice cloud filtering of such measurements. It has been shown that the stratospheric sulfate aerosol after the Mt. Pinatubo eruption introduced a characteristic spectral signature into IR limb spectra for the Improved Stratospheric And Mesospheric Sounder (ISAMS) (Grainger et al., 1993; Lambert et al., 1993), the Cryogenic Limb Array Etalon Spectrometer (CLAES) (Massie et al., 1996; Lambert et al., 1997), and the balloon-borne Michelson Interferometer for Passive Atmospheric Sounding (MIPAS-B) (Echle et al., 1998). Further, Echle et al. (1998) derived optical and microphysical parameters of stratospheric aerosol from MIPAS-B measurements. Studies using high-resolution IR spectra of the spaceborne IR limb instruments Cryogenic Infrared Spectrometers and Telescopes for the Atmosphere (CRISTA) (Offermann et al., 1999; Riese et al., 1999) and MIPAS (Fischer et al., 2008) present methods to detect PSCs and distinguish between the three PSC types (ice, supercooled ternary solutions, and nitric acid trihydrate) (Spang and Remedios, 2003; Spang et al., 2004, 2005; Höpfner et al., 2009; Spang et al., 2012). However, these studies are restricted to the stratosphere and do not tackle the discrimination between aerosol and ice clouds in the troposphere. Measurements of the High Resolution Dynamics Limb Sounder (HIRDLS) (Gille et al., 2008) provide a flag for four different cloud types in the troposphere and stratosphere $(1-$ unknown cloud, 2 - cirrus layer, 3 -extensive PSC, 4 -opaque cloud) and $12 \mu \mathrm{m}$ extinctions. HIRDLS measurements are also sensitive towards volcanic aerosol and forest fire smoke clouds, which the detection routine classifies as "unknown cloud" (Massie et al., 2007). However, not only aerosol is classified as "unknown cloud"; multilayer cloud structures and clouds of intermediate thickness between deep convection tower and isolated cirrus layer also fall into the "unknown cloud" category (Massie et al., 2007).

For the detection of clouds and aerosol in the troposphere and stratosphere, Spang et al. (2001) introduced the cloud 
index (CI) for CRISTA limb IR measurements. Later, the CI was adapted to MIPAS (Spang et al., 2004) and to the airborne CRISTA-New Frontiers (CRISTA-NF) (Spang et al., 2008). The MIPAS CI thresholds were optimized as a function of latitude and altitude (Sembhi et al., 2012). A first attempt to classify between tropospheric ice and liquid clouds in MIPAS spectra was made by Spang et al. (2012). Regarding the discrimination between ice clouds and volcanic ash, Griessbach et al. $(2012,2014)$ presented a method to detect volcanic ash in the troposphere and stratosphere with MIPAS. Also for MIPAS, Grainger et al. (2013) presented methods to identify volcanic plumes containing sulfur dioxide, sulfate aerosol, and volcanic ash.

Aerosol detection and the separation from ice clouds for IR limb emission measurements is by far not as elaborated as for IR nadir measurements. Also, the nadir methods cannot be simply applied to limb emission measurements as they have rather different sensitivities due to different measurement geometries and principles (emission lines in the limb spectra and absorption lines in the nadir spectra). However, the IR nadir classification techniques mentioned above demonstrate the capability of IR measurements to provide a separation between ice clouds and various aerosol types. Separating between aerosol and ice clouds constitutes the first step towards altitude-resolved IR limb emission aerosol measurements in the UTLS. This region is of particular interest as in the past chiefly due to the lack of measurements the impact of volcanic aerosol on radiative forcing in the lower stratosphere at high and midlatitudes has been underestimated (Ridley et al., 2014).

Here, we present a method to detect clouds and aerosol in the troposphere and stratosphere and to separate between aerosol and ice clouds for IR limb emission measurements. The paper describes the method and shows examples for altitude-resolved aerosol detection for three volcanic eruptions at polar, mid-, and tropical latitudes. First, we present the instruments and our radiative transfer model (Sect. 2). Then we introduce a method that allows aerosol and clouds to be detected in the troposphere as well as in the stratosphere (Sect. 3.1). Starting with the new aerosol and cloud detection we develop a method to distinguish between ice clouds and aerosol (Sect. 3.2). We apply the new method to MIPAS measurements in 2011 and present the results for three volcanic eruptions (the Grímsvötn (Iceland), Puyehue-Cordón Caulle (Chile), and the Nabro (Eritrea) eruptions) and compare them with Atmospheric Infrared Sounder (AIRS) $\mathrm{SO}_{2}$ and volcanic ash measurements (Sect. 4). Finally, we present our conclusions (Sect. 5).

\section{Instruments and forward model}

\subsection{MIPAS}

The IR limb sounder MIPAS measured high-resolution spectra in the thermal IR between 685 and $2410 \mathrm{~cm}^{-1}$ (Fischer et al., 2008). In our study we use the measurements of band A $\left(685-970 \mathrm{~cm}^{-1}\right)$ and band B $\left(1215-1500 \mathrm{~cm}^{-1}\right)$. MIPAS was mounted on ESA's Envisat and measured atmospheric profiles between 6 and $68 \mathrm{~km}$ altitude from July 2002 to March 2004 and between 7 and $72 \mathrm{~km}$ altitude from January 2005 to April 2012 in its nominal mode. MIPAS measured in the thermal IR from a nearly polar orbit providing complete latitudinal and longitudinal coverage at day- and nighttime. Due to a malfunction in 2004 MIPAS's original nominal operation mode, which comprised a spectral sampling of $0.025 \mathrm{~cm}^{-1}$ and a vertical sampling of $3 \mathrm{~km}$, had to be changed. In 2005 the spectral sampling was reduced to $0.0625 \mathrm{~cm}^{-1}$ and the vertical sampling below $20 \mathrm{~km}$ was increased to $1.5 \mathrm{~km}$ (Fischer et al., 2008). Also, the measurement geometry was modified so that MIPAS sampled down to $7 \mathrm{~km}$ in the polar regions and down to $10 \mathrm{~km}$ in the tropics (Fischer et al., 2008). For developing a method to detect aerosol and to demonstrate its viability we use MIPAS level $1 b$ calibrated radiances that are available at ESA (2015).

\subsection{AIRS}

For the comparison with the MIPAS aerosol measurements we use the AIRS level $1 \mathrm{~b}$ radiances that are available at NASA (2015). The IR nadir sounder AIRS (Aumann et al., 2003) is mounted on NASA's Aqua satellite launched in May 2002. The AIRS hyperspectral IR spectra between 3.7 and $15.4 \mu \mathrm{m}\left(649-2674 \mathrm{~cm}^{-1}\right)$ are obtained from measurements in the nadir and sub-limb observation geometry. Each scan consists of 90 footprints in the across-track direction and covers a distance of $1765 \mathrm{~km}$ on the ground. The footprint size is $13.5 \mathrm{~km} \times 13.5 \mathrm{~km}$ for nadir and $41 \mathrm{~km} \times 21.4 \mathrm{~km}$ for the outermost sub-limb views. AIRS measures 14.5 orbits and provides about 2.9 million spectra per day. This provides an excellent horizontal resolution with global coverage twice a day except for small gaps at mid- and low latitudes.

\subsection{Juelich Rapid Spectral Simulation Code (JURASSIC)}

For radiative transfer simulations of the MIPAS measurements we use the JURASSIC (Hoffmann et al., 2008). It applies the emissivity growth approximation (Gordley and Russell, 1981) for fast simulations in the mid-infrared spectral region. JURASSIC has been used for radiative transfer simulations and trace gas retrievals for various IR limb instruments (Hoffmann et al., 2008, 2009; Weigel et al., 2010; Ungermann et al., 2010) and for nadir sounders such as AIRS (Hoffmann and Alexander, 2009; Grimsdell et al., 2010). 
JURASSIC has been extended with a scattering module that allows radiative transfer simulations to be conducted including single and multiple scattering on aerosol and cloud particles (Grießbach, 2012; Griessbach et al., 2013). In this study, we use Mie calculations to determine the optical properties extinction coefficient, scattering coefficient, and phase function of cloud and aerosol particles. For the simulations presented here, we use a setup described in detail by Griessbach et al. (2014) with slight modifications. Here, the spectral sampling is $0.0625 \mathrm{~cm}^{-1}$ and the vertical sampling is $0.5 \mathrm{~km}$.

\section{Aerosol detection and ice cloud filtering}

\subsection{Aerosol and cloud detection}

\subsubsection{Index methods for aerosol and cloud detection}

The CI is the standard method to detect clouds and aerosol with MIPAS (Spang et al., 2001). It is defined as the ratio between the mean radiances around the $792 \mathrm{~cm}^{-1}$ band with strong $\mathrm{CO}_{2}$ emissions and the atmospheric window region around $833 \mathrm{~cm}^{-1}$ :

$\mathrm{CI}=\frac{\bar{I}_{1}\left(\left[788.25,796.25 \mathrm{~cm}^{-1}\right]\right)}{\bar{I}_{2}\left(\left[832.31,834.37 \mathrm{~cm}^{-1}\right]\right)}$,

where $\bar{I}_{1,2}$ is the mean radiance of each window. The CI is a continuous value, where large values indicate clear air conditions and small values indicate the presence of clouds or aerosol. In previous studies CI values below 1.8-6 have been used to indicate cloudy air and CI values above 6 indicate clear air (Spang et al., 2004, 2012; Sembhi et al., 2012). The CI detection threshold depends on altitude, latitude, and season, mainly because of the water vapour continuum contributing to the $833 \mathrm{~cm}^{-1}$ window radiance (Spang et al., 2004; Sembhi et al., 2012). The effect of the water vapour continuum is particularly pronounced at lower tropospheric altitudes.

Because the water vapour continuum absorption decreases with higher wavenumber (e.g. Roberts et al., 1976), we looked for additional windows at higher wavenumbers in MIPAS band A in order to achieve an altitude-, latitude-, and season-independent aerosol detection. For the selection of an appropriate window, which cannot be directly adopted from IR nadir measurements due to the strong trace gas emission lines measured in the IR limb geometry, we considered MIPAS clear air radiance profiles between about 7 and $25 \mathrm{~km}$ altitude. In the clear air profile in Fig. 1 bright colours indicate high radiances due to trace gas emissions and dark colours indicate atmospheric window regions with low radiances. These atmospheric windows are especially suited for aerosol detection, because trace gases have little impact here. The broad window around $830 \mathrm{~cm}^{-1}$ with low radiances at all altitudes is already used for the CI. Between about 940 and $970 \mathrm{~cm}^{-1}$ there are many narrow windows with low radiances between $\mathrm{CO}_{2}$ lines. The broadest of these windows

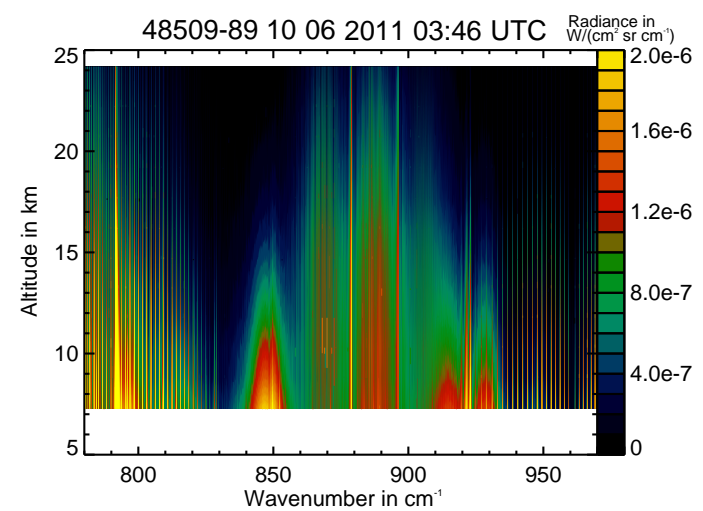

Figure 1. MIPAS radiances measured in profile 89 of orbit 48509 (around $48^{\circ} \mathrm{S}$ ). This clear air case shows low radiances in the broad window region around $830 \mathrm{~cm}^{-1}$ and multiple narrow windows between 950 and $970 \mathrm{~cm}^{-1}$.

is located between 960 and $961 \mathrm{~cm}^{-1}$. Therefore, we average over the 17 spectral points measured by MIPAS in this window and define the aerosol index (AI) as

$\mathrm{AI}=\frac{\bar{I}_{1}\left(\left[788.25,796.25 \mathrm{~cm}^{-1}\right]\right)}{\bar{I}_{2}\left(\left[960.00,961.00 \mathrm{~cm}^{-1}\right]\right)}$,

where $\bar{I}_{1,2}$ is the mean radiance of each window.

In the stratosphere at altitudes from about $50 \mathrm{~km}$ down to about $22 \mathrm{~km}$ we found a seasonal and diurnal cycle in the radiances between 960 and $961 \mathrm{~cm}^{-1}$ and hence in the AI (Fig. A1). This diurnal cycle and the differences between the summer and the winter hemisphere are most likely caused by non-local thermodynamic equilibrium (non-LTE) effects of the $\mathrm{CO}_{2}$ laser bands between 950 and $970 \mathrm{~cm}^{-1}$ at altitudes of $50 \mathrm{~km}$ and above (e.g. Timofeyev et al., 1995). In order to filter out this non-LTE feature we combined the AI with the CI, which is not affected by non-LTE effects, and defined the aerosol cloud index (ACI) as the maximum value of both:

$\mathrm{ACI}=\max (\mathrm{CI}, \mathrm{AI})$.

Below about $25 \mathrm{~km}$ the ACI generally corresponds to the $\mathrm{AI}$ and above about $25 \mathrm{~km}$ it corresponds to the $\mathrm{CI}$ (Fig. A1).

In order to demonstrate the benefits of the ACI and to derive a fixed threshold value that is applicable to MIPAS measurements, we investigated the behaviour of simulated and measured ACI profiles and compared them with the corresponding CI profiles.

\subsubsection{Simulations}

In the radiative transfer simulations we focused on clear air and cloud simulations at altitudes between 5.5 and $19.5 \mathrm{~km}$ with a $0.5 \mathrm{~km}$ vertical sampling. We considered polar winter, polar summer, midlatitude, and tropical atmospheric conditions (Remedios et al., 2007) without any background aerosol. The simulation results for clear air conditions (Fig. A3) show that the AI is significantly larger than 
the CI. They also show an altitude dependence for the CI but also for the AI/ACI especially at altitudes below $10 \mathrm{~km}$. At altitudes above about $15 \mathrm{~km}$ the $\mathrm{CI}$ and $\mathrm{AI}$ converge towards each other. In the polar summer atmosphere they intersect at $17 \mathrm{~km}$, which means that the ACI corresponds to the CI at altitudes above.

For the cloud simulations we placed $1 \mathrm{~km}$ thick ice cloud, sulfate aerosol, and volcanic ash layers at 6-7, 9-10, 13-14, and $17-18 \mathrm{~km}$ altitude in polar winter, polar summer, midlatitude, and tropical atmospheric conditions. For the ice cloud, volcanic ash, and sulfate aerosol simulations we assumed various realistic combinations of particle sizes, concentrations, and extinctions given at $948.5 \mathrm{~cm}^{-1}$ (see Tables 3-5 in Griessbach et al., 2014). The simulated extinction range was $1 \times 10^{-3}-1,1 \times 10^{-3}-5 \times 10^{-1}$, and $1 \times 10^{-4}-1 \times 10^{-2} \mathrm{~km}^{-1}$ for ice, volcanic ash, and sulfate aerosol, respectively. The considered mode radii were $0.3-96,0.1-5$, and $0.01-1.5 \mu \mathrm{m}$, respectively. Examples of simulated profiles for ice, volcanic ash, and sulfate aerosol are shown in Figs. A5 to A7.

While for clear air the AI/ACI values are systematically larger than the CI values both have similar values in case of sulfate aerosol and volcanic ash at cloud altitude. In some cases the AI becomes smaller than the CI, which means that it is even more sensitive towards the aerosol. Also, the deviation from the clear air profile is stronger for the AI than for the CI. For ice clouds, however, the CI is systematically smaller than the AI/ACI, which means that the CI is more sensitive towards ice. Since we focus on aerosol detection, this is not an issue for our study. More details on the simulated CI, AI, and ACI profiles and its sensitivity are discussed in the Appendix Sect. A3.

To derive an ACI aerosol/cloud detection threshold value we considered the simulated clear air profiles and the MIPAS measurement geometry after the modification in 2005 that reached down to about $10 \mathrm{~km}$ in the tropics and about $7 \mathrm{~km}$ in the polar regions. In the simulations the ACI is always larger than 7 in the polar winter atmosphere. In the polar summer and midlatitude atmosphere the ACI is larger than 7 at $7 \mathrm{~km}$ and above and in the equatorial atmosphere it is larger than 7 at $9 \mathrm{~km}$ and above. This means that a fixed ACI threshold value of 7 will be applicable to MIPAS measurements between 2005 and 2012 for the detection of aerosol.

\subsubsection{Measurements}

Examples of the CI (Fig. 2b), the AI (Fig. 2c), and the ACI (Fig. 2d) are shown as a function of altitude along a single MIPAS orbit (Fig. 2a) measured on 18 August 2011. In mid-August most of the northern hemispheric stratosphere was affected by a sulphate aerosol layer caused by the Nabro eruption in June 2011 (Bourassa et al., 2012; Fromm et al., 2014). Two months after the eruption of the Nabro volcano this layer was diluted, so that it was invisible to IR nadir measurements (Fig. 2f) and to the CALIPSO operational product (NASA, 2016) but visible to OSIRIS solar scattering mea- surements (Bourassa et al., 2012) and to MIPAS (Fig. 2d, e) as discussed below.

For the detection of aerosol and clouds along a MIPAS orbit we mainly rely on the established CI. Here we briefly discuss the purposes and shortcomings of the different $\mathrm{CI}$ thresholds for the example of a particular MIPAS orbit (Fig. 2b). A fixed CI threshold of 1.8 (CI below 2 shown in yellow) is used for cloud clearing for trace gas profile retrievals by ESA (Spang et al., 2004). This threshold captures tropospheric clouds only and PSCs in the Antarctic but not a volcanic aerosol layer in the northern hemispheric UTLS like the one caused by Nabro. Also, a fixed CI threshold of 4.5 (yellow, orange, red), which is used for more conservative cloud filtering, mainly captures PSCs (Höpfner et al., 2009), subvisible cirrus clouds (SVCs) (Spang et al., 2015), and tropospheric clouds but not the volcanic aerosol layer. A fixed CI threshold of 6 (yellow, orange, red, dark red) captures the UTLS aerosol layer but mistakes cloud-free regions (profiles 0-3, 56-60, and 92-95; see comparison with IR nadir data below) as cloudy. This feature of the CI of becoming smaller at lower altitudes in cloud-free conditions is addressed by Sembhi et al. (2012), providing a variable CI threshold definition at altitudes above $10 \mathrm{~km}$. Here we used a simplified variable CI threshold based on Sembhi et al. (2012). The details are given in Appendix A1. This most advanced CI threshold definition (black crosses in Fig. 2b and d) allows cloudy and cloud-free tropospheric regions as seen by IR nadir instruments (Fig. 2f) to be discriminated and captures the UTLS aerosol layer as observed by OSIRIS.

Figure 2 suggests that a fixed ACI with values smaller than 7 allows tropospheric clouds as well as the stratospheric aerosol layer caused by the Nabro eruption to be detected. Hence, we assessed the performance of the ACI with a fixed threshold value of 7 for the detection of aerosol and clouds by comparing the ACI aerosol/cloud detections with $\mathrm{CI}$ cloud detections relying on the thresholds presented by Sembhi et al. (2012) for altitudes above $10 \mathrm{~km}$ combined with a fixed CI threshold of 2 at $10 \mathrm{~km}$ and below (black crosses in Fig. $2 b$ and d). In Fig. 2b and d the profiles 0-3, 56-60, and 92-95 are identified as clear air by both the CI and the ACI. The UTLS aerosol layer is also captured by both. However, the $\mathrm{CI}$ and the ACI cloud/aerosol detections are not completely identical. Below $10 \mathrm{~km}$ the CI with a threshold of 2 identifies slightly less clouds than the ACI with a threshold of 7. Examples can be found in profiles 16, 18, and 19 around $10 \mathrm{~km}$ and between profiles 30 and 40, where the CI detects clear air down to the lowest tangent altitude, whereas the ACI indicates clouds at the lowest tangent altitude. Above $10 \mathrm{~km}$ there are a few profiles where the CI identifies clouds/aerosol but not the ACI and vice versa (e.g. profiles 5, 54, 41-44). However, the main differences can be seen in profiles 16-18, where the $\mathrm{CI}$ indicates clouds/aerosol down to the tropopause whereas the ACI indicates a stratospheric aerosol layer with clear air below, and between profiles 23 and 35, where the CI 
indicates a thin stratospheric aerosol layer whereas the ACI indicates aerosol down to the tropopause.

The tropospheric aerosol/cloud detections of the $\mathrm{CI}$ and ACI are confirmed by geostationary IR nadir measurements by MTSAT (15:00 UTC), IODC (18:00 UTC), and GOES East (15:00 UTC) (the IR nadir images were obtained from NERC Satellite Receiving Station, Dundee University, Scotland, http://www.sat.dundee.ac.uk/) along the orbit track (Fig. 2f) and closest to the MIPAS measurement time (15:0516:45 UTC). In the IR nadir images clear air is indicated by dark/black colours, high-altitude clouds are bright white, and low-altitude clouds are indicated by greyish colours. For the clear air profiles 0-2 north west of Australia (22-20 $\mathrm{S}), 53-$ 60 west of South America $\left(2^{\circ} \mathrm{N}-23^{\circ} \mathrm{S}\right)$, and $92-95$ over the Indian Ocean the IR nadir images show only low-altitude clouds, which are below the lowest tangent altitude of MIPAS. Over Asia $\left(7^{\circ} \mathrm{S}-15^{\circ} \mathrm{N}\right)$ many high-altitude clouds are present (profiles 4-15). Over northern China and Mongolia there is a gap in the high-altitude clouds (profiles 1718). Over North and Central America $\left(10-60^{\circ} \mathrm{N}\right)$ there are patchy cloud patterns, which is also reflected in the alternating cloudy and clear air profiles (profiles 38-51) measured by MIPAS. From 26 to $60^{\circ} \mathrm{S}$ (profiles 61-70) there is a large field of high-altitude clouds. At latitudes higher than $60^{\circ}$ the results from geostationary images become uncertain, hence they are not discussed here. A more detailed assessment of the detection sensitivity and altitude information accuracy of the MIPAS measurements of the UTLS aerosol layer will be presented in a future study.

\subsubsection{Discussion of the ACI detection threshold value}

The simulations as well as the comparison with the most sensitive variable $\mathrm{CI}$ threshold values indicated that a fixed ACI value of 7 is an appropriate threshold value. Hence, in the following we use the ACI with a fixed threshold value of 7 down to $7-9 \mathrm{~km}$ as an alternative to the $\mathrm{CI}$ with variable thresholds above $10 \mathrm{~km}$ and a fixed threshold of 2 below $10 \mathrm{~km}$. The example (Fig. 2) shows the advantage of the ACI, namely to have a fixed threshold that is sensitive to thin aerosol layers and thick clouds, while not mistaking tropospheric clear air as cloudy.

For the measurements before 2005 we also analysed altitudes below $7-9 \mathrm{~km}$. For these altitudes the simulations in Sect. 3.1.2 indicated that the ACI for clear air falls below 7 at altitudes below $7-9 \mathrm{~km}$. However, we often found ACI values significantly larger than 7 down to the lowest tangent altitudes (Figs. A2, A4) in the MIPAS measurements before 2005. As the most likely reason for the discrepancy between the measurements and simulations below $9 \mathrm{~km}$ we identified the water vapour continuum assumed in the simulations. On the one hand, we used climatological water vapour profiles that inherently do not cover the complete variability in the atmosphere; on the other hand, in JURASSIC the Mlawer-Tobin-Clough-Kneizys-Davies
1.10 scheme (MT_CKD) (Clough et al., 2005) is used for the water vapour continuum representation. This scheme was found to represent real conditions with insufficient accuracy at lower altitudes (Griessbach et al., 2013). Hence, the ACI has the potential to be also applied to the MIPAS measurements before 2005, where the lowest tangent altitude reached down to nearly $5 \mathrm{~km}$ at all latitudes.

\subsection{Ice cloud filtering}

\subsubsection{Window selection}

For the separation between aerosol and ice clouds by IR nadir measurements spectral windows around 8.5, 11, and $12 \mu \mathrm{m}$ $\left(1176,909,833 \mathrm{~cm}^{-1}\right.$, respectively) are employed (Ackerman, 1997; Guehenneux et al., 2015). For these windows the optical properties of ice differ most strongly from aerosol such as volcanic ash, soil-derived aerosol, and sulfate aerosol (Ackerman, 1997). For the IR limb emission measurements of MIPAS we identified three narrow windows that have very little interference with trace gases and exploit the spectral differences between the optical properties of ice and, in our case, volcanic aerosol:

$$
\begin{aligned}
& -830.6-831.1 \mathrm{~cm}^{-1} \\
& -960.0-961.0 \mathrm{~cm}^{-1} \\
& -1224.1-1224.7 \mathrm{~cm}^{-1} \text {. }
\end{aligned}
$$

Hereafter we refer to these windows as the 830, 960, and $1224 \mathrm{~cm}^{-1}$ windows.

The optical properties, i.e. extinction coefficient $\left(\beta_{\mathrm{e}}\right)$ and single scattering albedo, are determined by the microphysical properties of the particles, i.e. complex refractive index, particle size, and particle shape. The imaginary and real parts of the complex refractive indices of ice (Warren and Brandt, 2008), sulfate aerosol (Hummel et al., 1988), and two representatives of volcanic ash (Volz, 1973, volcanic ash; Pollack et al., 1973, basalt) are shown in Fig. 3a and b, where our windows are indicated by grey bars. The imaginary part of the refractive index (Fig. 3a) has a positive spectral gradient for ash and sulfate between 830 and $960 \mathrm{~cm}^{-1}$, whereas the spectral gradient of ice is negative. Also, between 830 and $1224 \mathrm{~cm}^{-1}$ the spectral gradient is positive for sulfate but negative for ice. For the real part of the refractive indices (Fig. 3b), the spectral gradient between 830 and $960 \mathrm{~cm}^{-1}$ is positive for ash and sulfate but negative for ice. The spectral gradient between 960 and $1224 \mathrm{~cm}^{-1}$ is negative for ash and sulfate but positive for ice.

As the imaginary part of the complex refractive index describes the absorption and the real part describes the scattering, these differences between ice clouds and aerosol (volcanic ash and sulfate aerosol) propagate to the optical properties (Fig. 3c and d). To calculate the extinction coefficient and single scattering albedo we used the same log-normal size distributions as Griessbach et al. (2014) for sulfate aerosol, 
(a)
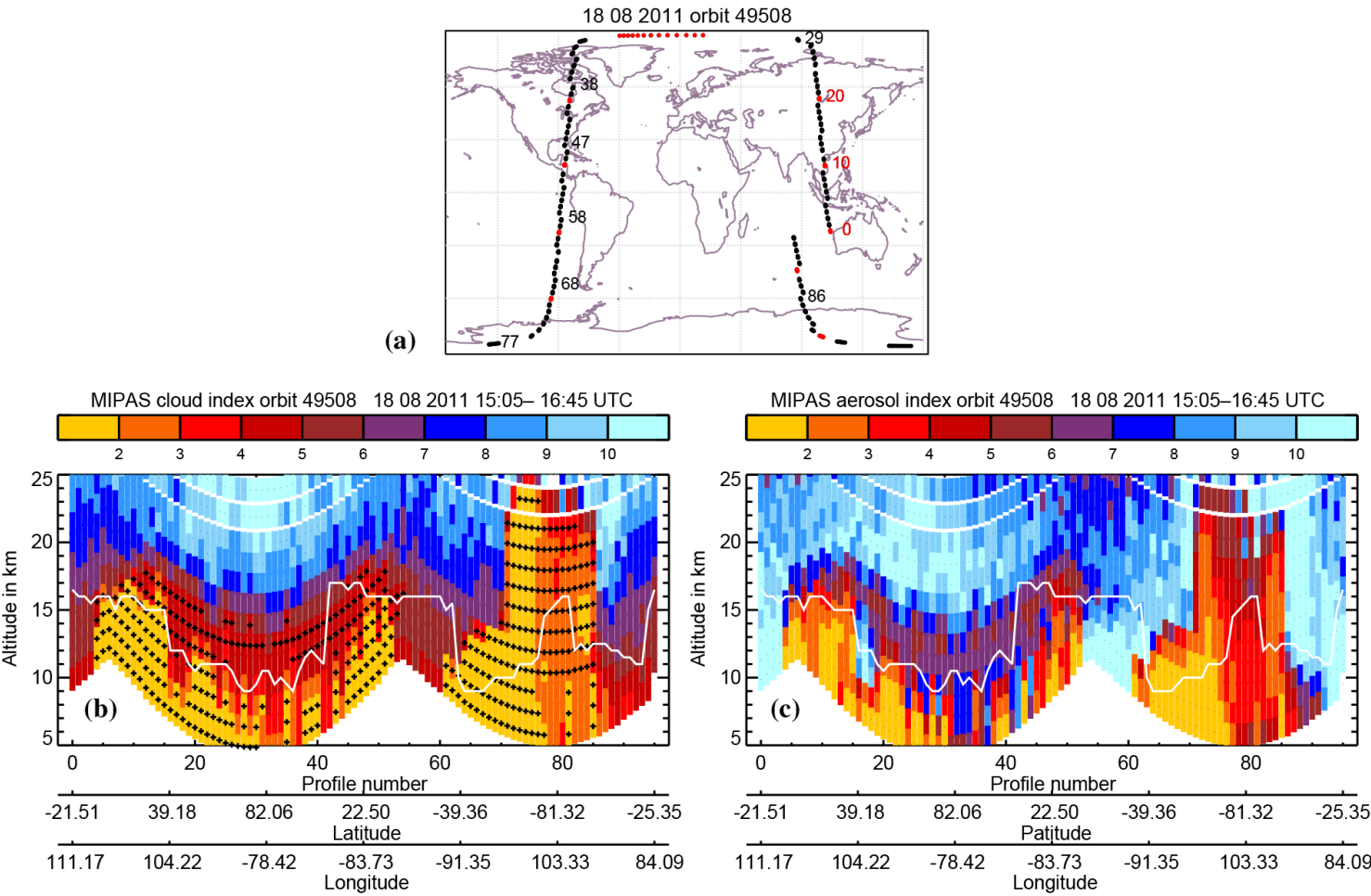

MIPAS cloud + aerosol index orbit $49508 \quad 18082011$ 15:05-16:45 UTC

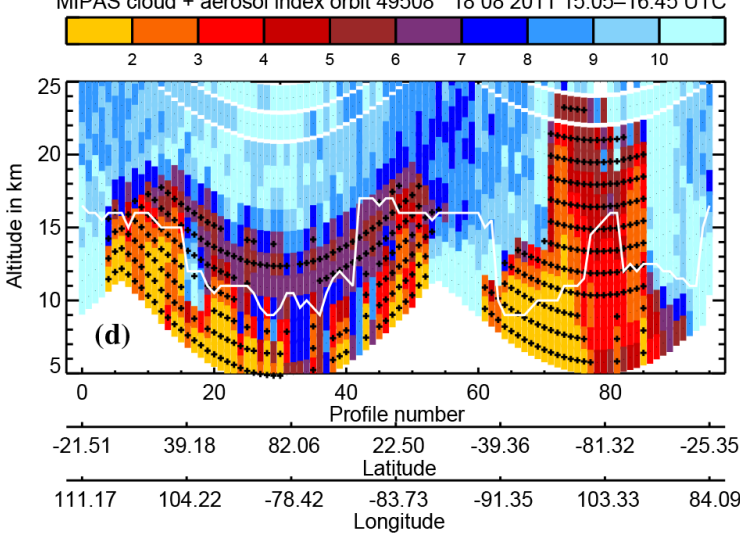

MIPAS cloud + aerosol index orbit 4950818082011 15:05-16:45 UTC
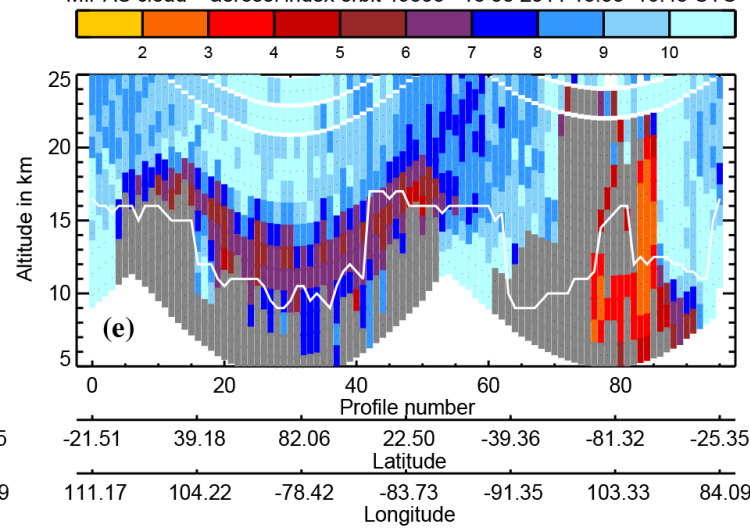

(f)
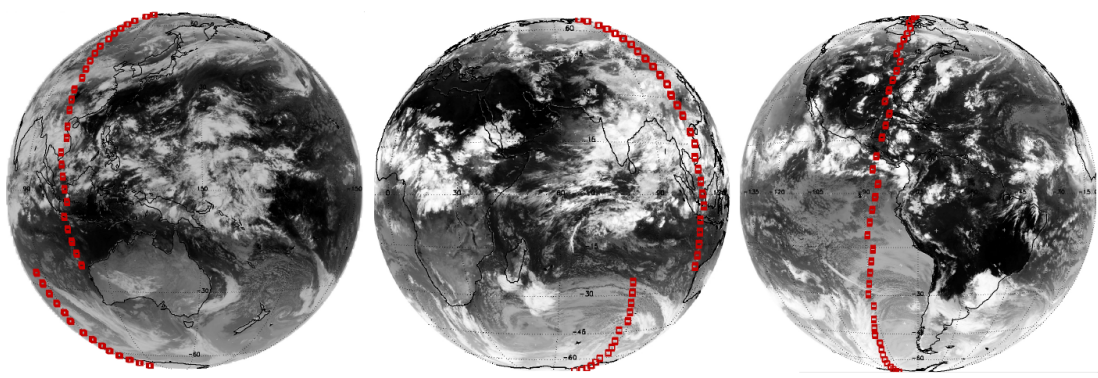

Figure 2. MIPAS profiles of orbit 49508 (a) measured on 18 August 2011 for (b) cloud index, (c) aerosol index, and (d) aerosol-cloud index, (e) aerosol-cloud index. Black crosses denote cloud/aerosol detections using a fixed CI threshold of 2 below $10 \mathrm{~km}$ and the variable threshold definition following (Sembhi et al., 2012) above $10 \mathrm{~km}$. White curves denote the thermal tropopause according to the World Meteorological Organization (WMO) definition along the orbit track derived from ERA-Interim data (Dee et al., 2011). In polar winter the thermal tropopause is often not present (Zängl and Hoinka, 2001). Ice and optically thick clouds (grey body radiators) are shown in grey. The IR nadir measurements of MTSAT, IODC, and GOES-East (f) are shown temporally closest to the MIPAS measurements. The IR nadir images were obtained from NERC Satellite Receiving Station, Dundee University, Scotland, http://www.sat.dundee.ac.uk/. 

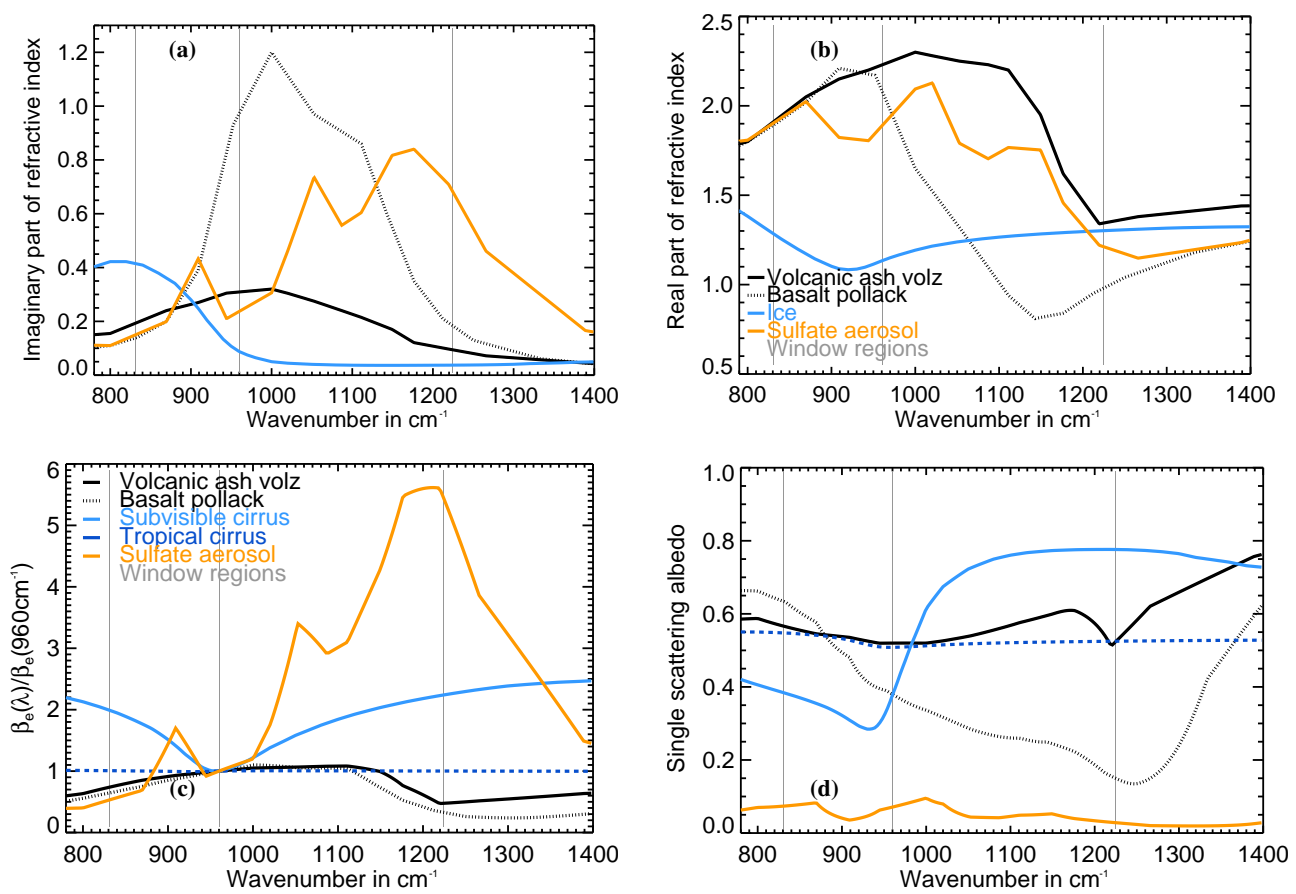

Figure 3. Microphysical properties of sulfate aerosol, ice, and two types of volcanic ash. (a, b) Complex refractive indices and their optical properties. (c) Extinction coefficient. (d) Single scattering albedo. The vertical lines indicate atmospheric window regions.

volcanic ash, subvisible cirrus (small ice particles), and tropical cirrus (large ice particles). The extinction coefficient spectra (Fig. 3c) were normalised to 1 at $960 \mathrm{~cm}^{-1}$. For sulfate aerosol and ash they exhibit similar spectral gradients as the imaginary part of the refractive index. However, in addition to the refractive indices, the particle size has an impact on the optical properties. For large ice particles the extinction coefficient spectrum is flat and for small ice particles it exhibits a pronounced minimum around $960 \mathrm{~cm}^{-1}$. The single scattering albedo depends on particle size and wavenumber (Fig. 3d). The scattering contributions range from 30 to $80 \%$ for small ice particles and are nearly constant around 55\% for large ice particles. The scattering contribution of the sulfate aerosol is generally below $10 \%$ and for volcanic ash it ranges from 15 to $80 \%$. Hence, scattering effects can not be neglected for any particle type discussed here.

\subsubsection{Simulations}

Having identified three window regions with small radiance contributions by atmospheric trace gases and with significant differences in the optical properties for ice and volcanic aerosol, we expected that these differences could also be found in the radiance spectra measured by MIPAS. For IR nadir measurements it is common practice to use brightness temperature differences (BTDs) for the discrimination between volcanic or soil-derived aerosol and ice clouds (e.g. Prata, 1989a; Ackerman et al., 1990; Ackerman, 1997). In order to identify characteristic patterns in BTD correlations for IR limb emission measurements, we evaluated the radiative transfer simulations for clear air, ice, volcanic ash, and sulfate aerosol under various atmospheric conditions (3.1.2). In contrast to IR nadir BTD analyses that often correlate $11-12 \mu \mathrm{m}$ with $8-11 \mu \mathrm{m}$ (e.g. Ackerman et al., 1990; Hong et al., 2010), we found for MIPAS IR limb spectra the clearest correlation patterns for the BTDs between the 830 and $1224 \mathrm{~cm}^{-1}(12.0-8.2 \mu \mathrm{m})$ windows and the 960 and $1224 \mathrm{~cm}^{-1}(10.4-8.2 \mu \mathrm{m})$ windows.

The simulation results are shown for all realistic ice cloud (Fig. 4a), sulfate aerosol (Fig. 4b), volcanic ash (Fig. 4c), and "clear air" (Fig. 4d) scenarios. The tangent altitudes of the simulations range from 6 to $19.5 \mathrm{~km}$, which is from above to below the simulated clouds. Except for the clear air simulations only the scenarios for ACI $<7$ are shown. In the simulations, the individual results for the BTDs are colour-coded by the ACI because we found a clear sensitivity to the ACI in the simulations. The solid black lines are nearly identical to the diagonal and split the plot into two parts (upper and lower part). Here, we use them to guide the reader through each panel of Fig. 4. In fact, these are our threshold functions that will be derived in Sect. 3.2.4.

The ice simulations (Fig. 4a) comprise extinctions ranging from 0.1 to $1 \mathrm{~km}^{-1}$ and mode radii ranging from 0.3 to $96 \mu \mathrm{m}$. They fall in the middle of the BTD correlation plot, forming a longish shape and reaching from negative BTDs to positive BTDs (about -45 to $5 \mathrm{~K}$ ) on both axes. Nearly all simulations fall into the lower part (below the nearly diagonal separation lines). In the little inset of Fig. 4a we filtered the 
comprehensive simulations for realistic combinations of particle sizes and extinctions (number concentrations). Hence, we removed all simulations with mode radii of $6 \mu \mathrm{m}$ and below and extinctions of $5 \times 10^{-2} \mathrm{~km}^{-1}$ and larger from the polar summer, midlatitude, and tropical atmosphere because we consider such small ice particle sizes and high extinction (number concentrations) only likely in PSCs (Deshler et al., 1994). SVCs may have such small ice particle sizes, but they inherently have lower extinctions (Iwasaki et al., 2007; de Reus et al., 2009; Frey et al., 2011). The ice simulations show a dependence on the ACI, where optically thick scenarios $(\mathrm{ACI}<2)$ form a narrow cluster below the black line at BTDs between 0 and $-20 \mathrm{~K}$. Optically less dense ice scenarios (ACI > 2) usually have a lower BTD on both or only one of both axes.

The sulfate simulations (Fig. 4b) performed for extinctions between $1 \times 10^{-4}$ and $1 \times 10^{-2} \mathrm{~km}^{-1}$ and mode radii between 0.01 and $1.5 \mu \mathrm{m}$ have ACI values ranging from larger than 2 to larger than 7 . None of the scenarios that include post-Pinatubo particle sizes and concentrations gets optically thick. Scenarios for the $1 \mathrm{~km}$ thick sulfate aerosol layer with an extinction coefficient of $1 \times 10^{-4} \mathrm{~km}^{-1}$ at $947 \mathrm{~cm}^{-1}$ $(10.5 \mu \mathrm{m})$ have ACIs larger than 7 and hence would be identified as clear air. Scenarios with extinction coefficients of $5 \times 10^{-4} \mathrm{~km}^{-1}$ and higher have ACIs below 7. They cluster above the diagonal at low BTDs (smaller than $-20 \mathrm{~K}$ on the $x$ axis). The scenarios that fall in the lower part of the plot are all for tangent altitudes below $8 \mathrm{~km}$. Comparing the sulfate aerosol simulations with the ice cloud simulations, there is nearly no overlap except for very few scenarios below $8 \mathrm{~km}$.

For the simulations of volcanic ash we used the "basalt" refractive indices (Pollack et al., 1973) (Fig. 4c) and the "volcanic ash" refractive indices (Volz, 1973) (not shown). The simulations that were performed for extinctions between $1 \times 10^{-3}$ and $5 \times 10^{-1} \mathrm{~km}^{-1}$ and mode radii between 0.1 and $5 \mu \mathrm{m}$ cover optically thick (ACI $<2$ ) to thin conditions. The simulated scenarios form a diagonal shape in the middle of the BTD correlation plot and extend from the lower left to the upper right of the plot. Also, a dependence on the ACI, similar to the ice cloud simulations, with high values (optically thin) at bottom left and small values (optically thick) at top right can be seen. Several ash simulations fall in the lower part of the plot and are congruent with the ice simulations. Hence, only the ash scenarios that fall in the upper part of the plot are separable from ice clouds. In the simulations we found a particle size dependency (not shown), where smaller particles fall in the upper part and larger particles fall in the lower part (ice region) of the plot. A size dependency for detecting volcanic ash with IR limb emission measurements has also been reported by Griessbach et al. (2014) with a maximum detectable mode radius of $1.5 \mu \mathrm{m}$ for volcanic ash (Volz, 1973). Here, for volcanic ash we found scenarios with a mode radius of $5 \mu \mathrm{m}$ that do not overlap with ice. From the simulations presented here, we derived that volcanic ash particles with mode radii between 0.3 and $5 \mu \mathrm{m}$ and extinction coefficients between $1 \times 10^{-3}$ and $5 \times 10^{-1} \mathrm{~km}^{-1}$ can be discriminated from ice clouds at altitudes down to $6 \mathrm{~km}$. Comparing the ash simulations with the sulfate simulations, there is substantial overlap. Hence, further criteria are required for the discrimination between sulfate aerosol and volcanic ash. As the focus here is on filtering out ice spectra from all cloudy spectra, we do not pursue an aerosol classification at this point.

Comparing the clear air simulations for the four atmospheres (polar winter, polar summer, midlatitudes, equatorial) at altitudes between 6 and $19.5 \mathrm{~km}$ (Fig. 4d) with the ice and aerosol simulations shows that there is an overlap. As already described in Sect. 3.1, there are a few simulated clear air scenarios with ACI $<7$ below $9 \mathrm{~km}$. However, all clear air scenarios at altitudes below $14 \mathrm{~km}$ fall in the lower part (ice region) of the BTD correlation plot and hence will be filtered out together with the ice scenarios. Some scenarios above $14 \mathrm{~km}$ fall in the upper part of the BTD correlation plot, but they all have an ACI $>10$. Using an ACI $<7$ as a pre-condition, these clear air scenarios will be filtered out also.

\subsubsection{Measurements}

Having expectations from the simulations on what the BTD correlations look like for ice clouds, sulfate aerosol, and volcanic ash, we show four selected cases of UTLS aerosol measurements in order to verify the simulations (Fig. 5). For each case we used all measurements of an entire day, which is about 14 orbits, in the latitude range given below and at altitudes between MIPAS lowest tangent altitude (about $7 \mathrm{~km}$ ) and $25 \mathrm{~km}$. For the longitude range we did not introduce a limitation in order to include also clear air and ice clouds. In Fig. 5 all spectra with cloud/aerosol detections $(\mathrm{ACI}<7)$ are shown. Targeting at successfully filtering out ice clouds, we expect that the aerosol clearly stands out from the ice region as indicated by the simulations. For better comparison we also added the nearly diagonal separation lines introduced in Fig. 4.

For 17 May 2011 (Fig. 5a) we expected to find only ice clouds after filtering out the clear air spectra in the entire Southern Hemisphere at latitudes between 0 and $60^{\circ} \mathrm{S}$ (since there are no reports of volcanic eruptions; Smithsonian Global Volcanism Programme, 2016). As in the ice cloud simulations (Fig. 4), the measurements with ACI $<7$ form a relatively narrow diagonal group with BTDs ranging from 0 to $-40 \mathrm{~K}$ on both axes.

For 29 July 2011 (Fig. 5b) we expected to find sulfate aerosol from the Nabro eruption covering the entire northern hemispheric UTLS $\left(0-90^{\circ} \mathrm{N}\right)$ (Bourassa et al., 2012) and ice clouds as well. In the measurements with $\mathrm{ACI}<7$ we again observe a relatively narrow diagonal group just below the separations lines as in the ice simulations. In addition there is a second cluster with ACI values between 5 and 7 and at BTDs between -30 and $-50 \mathrm{~K}$ on the abscissa and 

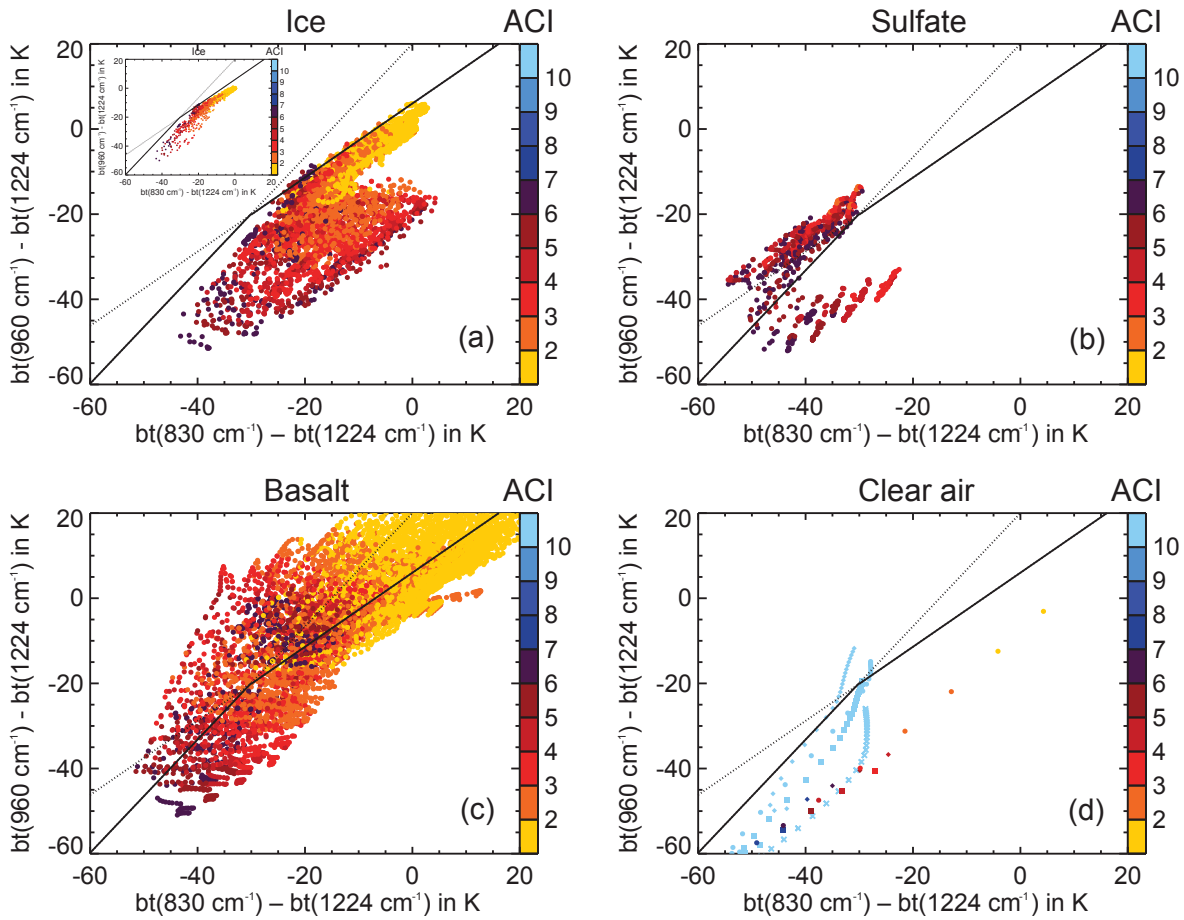

Figure 4. Simulated brightness temperature difference correlations for (a) ice clouds, (b) sulfate aerosol, (c) volcanic ash (here basalt from Pollack et al. (1973) is shown), and (d) clear air. The ice cloud simulations are shown for mode radii ranging from 0.3 to $96 \mu \mathrm{m}$. In the small inset ice simulations are only shown for mode radii ranging from 12 to $96 \mu \mathrm{m}$. For the clear air simulations the atmosphere type is indicated by the following symbols: polar winter - crosses; polar summer - diamonds; midlatitudes - squares; equatorial - circles. The black lines are the ice separation thresholds, where the solid part of each line denotes the relevant part for the discrimination between aerosol and ice.

between -20 and $-40 \mathrm{~K}$ on the ordinate, just as expected from the simulations for sulfate aerosol (Fig. 4b).

For 16 June 2011 (Fig. 5c) we expected to find volcanic ash at latitudes between 0 and $60^{\circ} \mathrm{S}$ originating from the eruption of the Puyehue-Cordón Caulle (Klüser et al., 2013) and ice clouds as well. As seen in the two cases before, in the measurements with $\mathrm{ACI}<7$ there is again a relatively narrow diagonal group just below the separation lines as predicted by the ice simulations. Furthermore, there are many spectra above the separation lines forming an arc-shaped structure and with ACI values ranging from below 2 to 7 . These measurements fall in the region covered by the volcanic ash simulations (Fig. 4a).

For 29 January 2011 (Fig. 5d) we again expected to find tropospheric ice clouds after filtering out clear air spectra and polar stratospheric clouds in the Northern Hemisphere $(0$ $90^{\circ} \mathrm{N}$ ). As in the cases before, there is the narrow diagonal ice group with ACI values ranging from below 2 to 7 , but there is also a second cluster just above the separation lines with ACI values ranging from below 2 to 7 . If only measurements between 0 and $60^{\circ} \mathrm{N}$ are considered, the second cluster disappears (Fig. A8). This example demonstrates that non-ice PSCs can also be separated from ice PSCs using this BTD correlation. To determine the non-ice PSC types, particle sizes and concentrations that can be separated from ice
PSCs with this method require detailed simulations which are not within the scope of this study. The classification of PSCs measured by IR limb sounders is the subject of multiple studies (Spang et al., 2012, 2015, and references therein).

\subsubsection{Definition of the ice filtering threshold and discussion}

As the simulations and measurements showed, the ice scenarios fall in the lower half of the BTD correlation plot and a substantial number of the aerosol simulations (volcanic ash and sulfate aerosol) falls in the upper half (Figs. 4 and 5). In order to deduce an ice filtering threshold for MIPAS measurements, we analysed the 2011 MIPAS data on a day-byday basis and analysed monthly and annual count statistics. From these we found that filtering out the ice clouds is best done with two threshold functions. For ACI values below 4 the upper edge of the ice cluster (BTDs larger than $30.4 \mathrm{~K}$ on the $x$ axis) is very sharp in the simulations (Fig. 4a) as well as in the measurements (Fig. 5). The corresponding threshold function is

$$
\mathrm{BTD}_{960-1224}=0.87 \times \mathrm{BTD}_{830-1224}+6 \mathrm{~K} .
$$



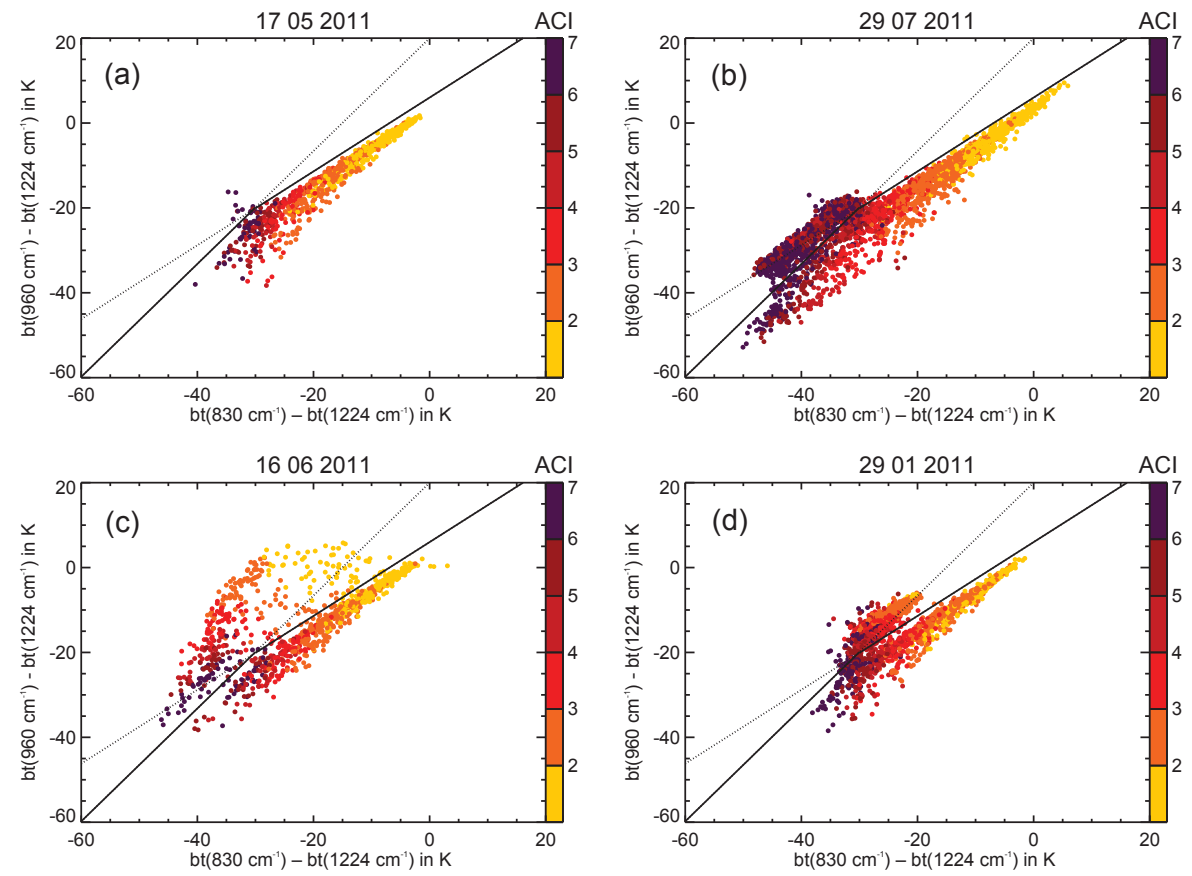

Figure 5. MIPAS brightness temperature difference correlations for selected scenarios: (a) ice clouds $\left(0-60^{\circ} \mathrm{S}\right)$, (b) Nabro sulfate aerosol $\left(0-90^{\circ} \mathrm{N}\right)$ and ice clouds, (c) Puyehue-Cordón Caulle volcanic ash $\left(0-60^{\circ} \mathrm{S}\right)$ and ice clouds, and (d) PSCs $\left(0-90^{\circ} \mathrm{N}\right)$ and tropospheric ice clouds. All figures comprise all orbits (about 14) measured on the day given on top of each plot. The black lines are the ice separation thresholds derived from the observations, where the solid part of each line denotes the relevant part for the discrimination between aerosol and ice.

For ACI values larger than 4 the BTD scatter plot can become quite diffuse for 2011 because there were three volcanic eruptions (Grímsvötn, Puyehue-Cordón Caulle, Nabro) that injected a substantial amount of $\mathrm{SO}_{2}$ and volcanic ash into the atmosphere. We also analysed the measurements from 2003, a year with very little volcanic emissions during the MIPAS measurement period. For BTDs below $-30.4 \mathrm{~K}$ we obtained the following threshold function:

$\mathrm{BTD}_{960-1224}=1.33 \times \mathrm{BTD}_{830-1224}+20 \mathrm{~K}$.

To identify aerosol in the MIPAS data we used the condition that the BTDs must exceed at least one of the two threshold functions given in Eqs. (4) and (5) (in Fig. 5 the black solid lines must be exceeded).

For the MIPAS orbit discussed in Sect. 3.1 the result using our ice filtering thresholds is shown in Fig. 2e. Figure 2e shows the ACI as in Fig. 2d but indicating in grey all spectra that fall in the ice region. As expected (see Sect. 3.1), nearly all aerosol/cloud detections in the northern hemispheric troposphere are identified as ice clouds. On top of these ice clouds there is a layer in the UTLS with ACI values between 4 and 7, which is the Nabro sulfate aerosol. In the Antarctic region a large fraction of the stratospheric clouds falls in the ice region, which can be expected in southern hemispheric winter, but around profiles 83-85 non-ice PSCs are also identified, consistent with the report of a NAT belt in the region downstream of the Antarctic peninsula (Höpfner et al., 2006).

Considering Eqs. (4) and (5) derived from 2 years of MIPAS measurements $(2003,2011)$ and the ice simulations (Fig. 4a), it becomes obvious that the line corresponding to Eq. (4) is very close to the simulations and that there is a gap between the line corresponding to Eq. (5) and the simulation results. Comparing the measurements (Fig. 5) and the simulations in more detail, we found that the narrow ice pattern below the threshold functions in the measurements is mostly reproduced by the ice cloud simulations. Especially for ACI values below 2 simulations and measurements agree well. However, for higher ACI values there are many scenarios that fall in a range that was not covered by the measurements (about 0 to $-40 \mathrm{~K}$ on the abscissa and -20 to $-50 \mathrm{~K}$ on the ordinate). These scenarios have in common that the assumed mode radius of the particles is $6 \mu \mathrm{m}$ or smaller and the extinction coefficient is smaller than or equal to $1 \times 10^{-2} \mathrm{~km}^{-1}$. We considered such small ice particles to be likely for ice PSCs (Deshler et al., 1994) and possibly SVCs (Iwasaki et al., 2007; de Reus et al., 2009; Frey et al., 2011). However, in the tropics and at midlatitudes we could not find MIPAS measurements that fall into this range. Hence, according to the MIPAS measurements $1 \mathrm{~km}$ thick ice clouds with mode radii smaller than $6 \mu \mathrm{m}$ seem very unlikely in the tropics and at midlatitudes. Only in the polar regions, which are excluded 
in Fig. 5a, b, c, did we find MIPAS measurements that show the same BTDs as the ice cloud simulations for mode radii down to $3 \mu \mathrm{m}$.

As already discussed in Sect. 3.2.2, there are a few simulated scenarios in the tropical atmosphere for the $18 \mathrm{~km}$ ice cloud that slightly exceed the upper threshold function. For these particular scenarios we assumed mode radii of $6 \mu \mathrm{m}$ or less and the extinction coefficients are between $5 \times 10^{-2}$ and $1 \mathrm{~km}^{-1}$. In the tropics mode radii of $6 \mu \mathrm{m}$ or less can only be found in SVCs. However, SVCs do not have such high particle concentrations and extinctions (Iwasaki et al., 2007; de Reus et al., 2009; Frey et al., 2011). Hence, in the inset of Fig. 4a the simulation results are shown only for ice particle size distributions with mode radii larger than $6 \mu \mathrm{m}$. The pattern of these ice cloud simulations is in very good agreement with the measurements shown in Fig. 5. Further all, but 7 out of 3333, simulated scenarios fall below the threshold functions derived from the measurements. These seven scenarios occur only for the ice cloud at $18 \mathrm{~km}$ altitude in the tropics and they all have a BTD larger than $-25 \mathrm{~K}$ on the abscissa. We checked the MIPAS measurements between $20^{\circ}\left(30^{\circ}\right) \mathrm{N}$ and $20^{\circ}\left(30^{\circ}\right) \mathrm{S}$ and found that in $48(62)$ out of 58945 (78 563) cloudy profiles in 2011 the upper threshold was exceeded (both $0.08 \%$ ). In 2003, a year with less volcanic aerosol, only 15 (18) out of 56375 (74 767) (0.02$0.03 \%$ ) cloudy profiles exceeded the upper threshold. Although we do not consider $0.02-0.08 \%$ to be a strong evidence in the measurements that tropical high-altitude clouds consisting of small ice particles could exceed the ice separation threshold, we would like to point out that there is at least the theoretical possibility.

The sulfate aerosol simulations (Fig. 4b) form a group just above the lower threshold function. This group matches very well the sulfate aerosol observations after the Nabro eruption (Fig. 5b). There are also a few scenarios for which the simulated BTD does not exceed the aerosol detection threshold. These scenarios occur all at tangent altitudes below $8 \mathrm{~km}$. However, in the MIPAS measurements we found numerous cases of aerosol detection below $8 \mathrm{~km}$ altitude. This is most likely due to the fact that the aerosol layers in reality have a larger vertical extent than the $1 \mathrm{~km}$ assumed in the simulations. This effect and an analysis of the altitude information including comparisons with lidar measurements will be discussed in detail in a separate study.

The volcanic ash simulations using "basalt" refractive indices reported by Pollack et al. (1973) (Fig. 4c) represent the volcanic ash measurements after the Puyehue-Cordón Caulle eruption (Fig. 5c) better than simulations using the "volcanic ash" refractive indices reported by Volz (1973). Thus, the volcanic ash simulations are very sensitive to the refractive index data and therefore to the type of volcanic ash present.

\section{Examples for application and verification}

We applied our new aerosol detection method to the MIPAS measurements in 2011. We detected aerosol mainly after volcanic eruptions. In Fig. 6 three examples for aerosol detections after the Grímsvötn, Puyehue-Cordón Caulle, and Nabro eruption are presented. To verify our results we compared the MIPAS aerosol detections with $\mathrm{SO}_{2}$ and ash detections by AIRS. Note that gas-phase $\mathrm{SO}_{2}$ is emitted by volcanic eruptions and conversion to liquid sulfate $\left(\mathrm{H}_{2} \mathrm{SO}_{4}\right)$ starts immediately after injection into the atmosphere by oxidation (von Glasow et al., 2009). For our comparisons of the horizontal plume locations we used the $\mathrm{AIRS} \mathrm{SO}_{2}$ index and the AIRS ash index by Hoffmann et al. (2014). High $\mathrm{SO}_{2}$ index values indicate high $\mathrm{SO}_{2}$ concentrations and high ash index values indicate high ash concentrations.

A U-shaped highly confined $\mathrm{SO}_{2}$ filament was measured by AIRS on 27 May 2011, 6 days after the initial eruption of the Grímsvötn volcano (Fig. 6a). The black dashed curves indicate the MIPAS tracks measured between 00:00 and 12:00 UTC. Symbols along the MIPAS track indicate aerosol detections. The symbols are coloured in shades of blue and green representing the aerosol observation top altitude. In addition to our new aerosol detection method, we looked for volcanic ash using the volcanic ash detection method reported by Griessbach et al. (2014). As we could not detect volcanic ash in all four profiles, the volcanic aerosol particles are most likely sulfate aerosol. The $\mathrm{SO}_{2}$ measured by AIRS is the precursor gas to sulfate aerosol measured by MIPAS. Since both $\mathrm{SO}_{2}$ and sulfate aerosol can be detected, the $\mathrm{SO}_{2}$ oxidised only partially during the 6 days after the eruption and the AIRS and MIPAS measurements agree well in location. While the AIRS data provide a high-horizontalresolution picture of the volcanic plume the MIPAS data add altitude information.

In Fig. $6 \mathrm{~b}$ the Nabro $\mathrm{SO}_{2}$ plume is shown on 17 June 2011, 3 days after the initial eruption. The MIPAS tracks were measured between 00:00 and 12:00 UTC. The Nabro emissions were entrained in the Asian monsoon circulation and first were transported northwards and later on eastwards. Where the MIPAS tracks cross the $\mathrm{SO}_{2}$ plume measured by AIRS, MIPAS detects aerosol. In the MIPAS measurements we found mineral material using the MIPAS ash detection method (Griessbach et al., 2014) in 2 out of 20 aerosol profiles at altitudes below $10 \mathrm{~km}$ (over the Arabian peninsula and the Iranian plateau). Based on this finding and studies by Fairlie et al. (2014) and Penning de Vries et al. (2014) we conclude that the Nabro plume mainly consists of sulfate aerosol, especially at higher altitudes. There are also some aerosol detections over the North Sea and Siberia at altitudes below $12 \mathrm{~km}$ that do not coincide with enhanced $\mathrm{SO}_{2}$. Based on MIPAS measurements we deduced that these aerosol particles originated from the Grímsvötn eruption about 1 month earlier. It is expected that 4 weeks after this eruption the emitted $\mathrm{SO}_{2}$ is completely oxidised and converted to sulfate 

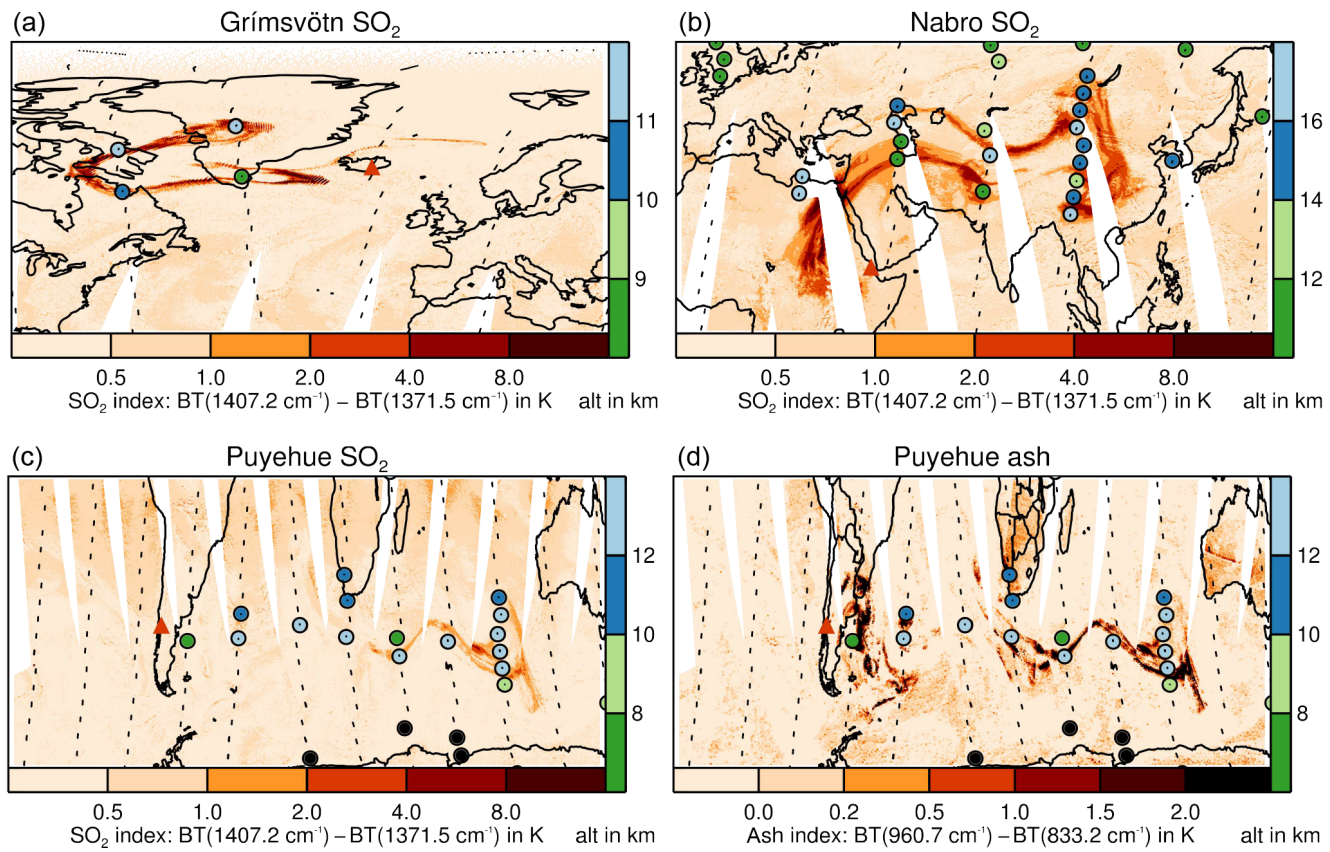

Figure 6. AIRS volcanic emission contours and MIPAS aerosol detections (coloured circles). (a) AIRS $\mathrm{SO}_{2}$ index for Grímsvötn (27 May 2011, a.m.); (b) AIRS SO 2 index for Nabro (17 June 2011, a.m.); (c) AIRS SO 2 index for Puyehue-Cordón Caulle (9 June 2011, p.m.); (d) AIRS ash index for Puyehue-Cordón Caulle (9 June 2011, p.m.). Non-ice PSCs in the Antarctic at altitudes above $18 \mathrm{~km}$ are coloured in black. The red triangles indicate the location of the respective volcanoes. Please note the different altitude scales.

aerosol (von Glasow et al., 2009) and hence can no longer be seen in the AIRS $\mathrm{SO}_{2}$ measurements (Hoffmann et al., 2016).

The AIRS $\mathrm{SO}_{2}$ index (Fig. 6c) and the ash index (Fig. 6d) were measured on 9 June 2011, 3 days after the initial eruption of the Puyehue-Cordón Caulle. The corresponding MIPAS tracks were measured between 12:00 and 24:00 UTC. Aerosol detections above $18 \mathrm{~km}$ are coloured in black and are related to non-ice PSCs that are present in each Antarctic winter (Pitts et al., 2013). Due to a strong jet stream the volcanic emissions were transported eastwards very quickly. The $\mathrm{SO}_{2}$ plume (Fig. 6c) stretches from the southern tip of Africa to the Indian Ocean just south-west of Australia. The Puyehue-Cordón Caulle plume was rich in ash as shown by the AIRS ash index (Fig. 6d), which shows an ash plume extending from west of Australia over South Africa and along the way back to South America. Between South America and South Africa there is no enhanced $\mathrm{SO}_{2}$ visible in the AIRS data. The comparison with the MIPAS aerosol detections based on the method presented here shows that very close to the eastern plume front there are six MIPAS profiles in a row indicating the presence of aerosol. These MIPAS detections are slightly westward of the plume front measured by AIRS, which is due to a temporal shift (up to $12 \mathrm{~h}$ ) between the AIRS and MIPAS measurements. The comparison of the MIPAS aerosol detections with the AIRS ash detections shows a good agreement (Fig. 6d). Using the MIPAS ash detection technique (Griessbach et al., 2014) we found ash in 10 out of 16 MIPAS aerosol profiles.

For the three examples of fresh volcanic plumes in the polar, midlatitude, and tropical atmosphere we found that the aerosol detection method introduced for IR limb emission measurements (see Sect. 3) performs well and also agrees well with AIRS volcanic emission measurements. However, in contrast to AIRS volcanic emission measurements (ash and $\mathrm{SO}_{2}$ ) the MIPAS volcanic emission measurements (comprising $\mathrm{SO}_{2}$ (Höpfner et al., 2013), ash (Griessbach et al., 2014), and sulfate aerosol from this study) can trace volcanic emissions in the form of ash and sulfate aerosol for much longer timescales (e.g. from June 2011 until April 2012 in case of the Nabro eruption, not shown). This is due to a higher sensitivity of MIPAS to the aerosol and due to the fact that $\mathrm{SO}_{2}$ is converted to sulfate aerosol on a timescale of about 4 weeks. These examples also demonstrate that IR limb emission measurements provide valuable altitude information. In a recent visualisation study, Günther et al. (2016) reconstructed 3-D volcanic emission plumes of the Nabro and Puyehue-Cordón Caulle by combining MIPAS aerosol and AIRS volcanic emission measurements with forward and backward trajectories started at the location of MIPAS aerosol detections. 


\section{Summary and conclusions}

We introduced a two-step method to detect aerosol in the troposphere and stratosphere with IR limb emission measurements. In the first step we identified a window region in the MIPAS spectra that is sensitive towards aerosol and clouds. In addition to the widely used CI that is very sensitive to clouds, we defined the AI that is more sensitive to aerosol by using the identified window at $960 \mathrm{~cm}^{-1}$. The AI has the advantage of being less altitude dependent in the troposphere than the CI. We combined the advantages of the AI in the troposphere and the $\mathrm{CI}$ in the stratosphere in a new index, the $\mathrm{ACI}$, which is the maximum of the $\mathrm{CI}$ and the AI. The ACI is more sensitive towards aerosol and provides a better contrast to clear air over the whole UTLS than the CI. Instead of varying CI threshold values ranging from 2 to 6 depending on altitude, region, and season, we found that a constant ACI threshold value of 7 is an appropriate global value for the detection of enhanced aerosol and clouds.

In the second step we developed a method to discriminate between ice clouds and aerosol for IR limb emission spectra with an ACI below 7. We used measured MIPAS spectra and simulations of optical properties for ice and volcanic aerosol employing typical size distributions (volcanic ash and sulfate aerosol) to identify appropriate windows for the discrimination. Three windows at 830,960 , and $1224 \mathrm{~cm}^{-1}$ that sample the contrasting behaviour of ice and aerosol are combined by brightness temperature difference correlations. We investigated the BTD correlations for the MIPAS measurements and selected scenarios where we expected to find ice clouds only, significant amounts of volcanic ash, volcanic sulfate aerosol, or non-ice PSCs. From these measurements we derived two threshold functions that separate between ice clouds and aerosol in MIPAS measurements.

To corroborate and further characterise the threshold functions we conducted radiative transfer simulations of ice clouds and aerosol layers. The simulations showed that ice clouds fall below the thresholds and aerosol can exceed the thresholds. Only for the rare case of optically thick $\left(\beta_{\mathrm{e}} \geq\right.$ $5 \times 10^{-2} \mathrm{~km}^{-1}$ ) ice clouds at $18 \mathrm{~km}$ altitude in the tropics could the threshold function be exceeded ( 7 out of 3333 scenarios). However, we consider these scenarios to be very unlikely and found this confirmed by the measurements. The simulations further showed that all realistic sulfate aerosol scenarios with $\beta_{\mathrm{e}}\left(948 \mathrm{~cm}^{-1}\right)>1 \times 10^{-4} \mathrm{~km}^{-1}$ above $8 \mathrm{~km}$ tangent altitude can be discriminated from ice clouds. For ash clouds the simulations showed that several scenarios can be distinguished from ice clouds. Detectable ash cloud scenarios had extinction coefficients (at $948 \mathrm{~cm}^{-1}$ ) between $1 \times 10^{-3}$ and $5 \times 10^{-1} \mathrm{~km}^{-1}$, mode radii between 0.3 and $5 \mu \mathrm{m}$, and reached down to $6 \mathrm{~km}$ tangent altitude.
A comparison of MIPAS measurements with horizontal high-resolution AIRS $\mathrm{SO}_{2}$ and ash index measurements for three strong volcanic eruptions in 2011 that were either characterized by large $\mathrm{SO}_{2}$ (Grímsvötn, Nabro) or volcanic ash emissions (Puyehue-Cordón Caulle) demonstrated the viability of our aerosol detection method. This comparison and a recent study (Günther et al., 2016) also point to the additional benefit of MIPAS altitude-resolved volcanic aerosol detection. The IR limb emission measurements can be used to quickly assign an altitude to the volcanic plume filaments measured by nadir instruments.

We consider our new aerosol detection method to be adaptable to other hyper-spectral IR limb instruments such as CRISTA, CRISTA-NF, MIPAS balloon (MIPAS-B) (Oelhaf et al., 1994), MIPAS-STRatospheric aircraft (MIPAS-STR) (Woiwode et al., 2012), and Gimballed Limb Observer for Radiance Imaging of the Atmosphere (GLORIA) (FriedlVallon et al., 2014; Riese et al., 2014). Although MIPAS is no longer operating there are 10 years of MIPAS measurements available and the new aerosol detection method in conjunction with the volcanic ash detection method (Griessbach et al., 2014) opens up new perspectives for the analysis of enhanced aerosol in the UTLS and volcanic eruptions based on IR limb emission measurements.

\section{Data availability}

The data used for Figs. 1, 2, 4, 5, 6, A1, A2, A4, and A8 can be reproduced by downloading the MIPAS Level $1 \mathrm{~b}$ calibrated radiances from ESA (2015) and applying the methods described in this paper. The IR nadir images in Fig. $2 \mathrm{f}$ were obtained from NERC Satellite Receiving Station, Dundee University, Scotland (http://www.sat.dundee.ac.uk/). To generate Fig. 6 we used AIRS levellb radiances that are available at NASA (2015) and applied the index methods described by Hoffmann et al. (2014). Access to the AIRS SO and ash index data can be obtained by contacting Lars Hoffmann (1.hoffmann@fz-juelich.de). Access to the complete data record of the MIPAS aerosol detections and the radiative transfer simulation results can be obtained by contacting the leading author (s.griessbach@fz-juelich.de). 


\section{Appendix A:}

\section{A1 Variable CI thresholds}

The variable CI thresholds between 10 and $25 \mathrm{~km}$ used in this study were derived from Fig. 2 in Sembhi et al. (2012). Because of very similar threshold profiles at these altitudes, we extracted the threshold profiles for three latitude bands given in Table A1 and used them for the Northern and Southern hemispheres. At each altitude we used the smallest integer threshold value in the corresponding latitude band. In the polar region we neglected the simulated profile for Antarctic winter because it "shows a large degree of uncertainty" (Sembhi et al., 2012).

\section{A2 Aerosol and cloud detection}

In the MIPAS measurements we found enhanced radiances in the $960 \mathrm{~cm}^{-1}$ window in the stratosphere at $50 \mathrm{~km}$ and below due to non-LTE effects of the $\mathrm{CO}_{2}$ laser bands (Timofeyev et al., 1995). These radiances affect the AI and cause low AI values that indicate incorrectly the presence of aerosol and clouds at UTLS altitudes. The $830 \mathrm{~cm}^{-1}$ window is not affected and therefore, as discussed in Sect. 3.1, we defined the ACI. Figure A1 illustrates the differences between the CI and the $\mathrm{AI}$ in the middle stratosphere. Comparing the $\mathrm{CI}$ and AI with the ACI illustrates that in the middle stratosphere the ACI is the CI and in the troposphere the ACI is the AI. The spectra coloured in white are filtered out because the radiances in at least one of the windows used in this study were below the MIPAS noise:

$$
\frac{N}{\sqrt{n}},
$$

where the MIPAS noise equivalent radiance $N$ is $3 \times 10^{-4} \mathrm{~W}\left(\mathrm{~m}^{2} \mathrm{srcm}^{-1}\right)^{-1}$ in band $\mathrm{A}$ and $2 \times 10^{-4} \mathrm{~W}\left(\mathrm{~m}^{2} \mathrm{srcm}^{-1}\right)^{-1}$ in band B (Kleinert et al., 2007) and $n$ is the number of spectral points.

Figure A1 shows the characteristic MIPAS measurement geometry after 2005 where the lowest tangent altitude follows the slope of the tropopause with a high tropopause in the tropics and a low tropopause in polar regions. The vertical sampling in the UTLS is $1.5 \mathrm{~km}$. The measurement geometry before 2005 is shown for the ACI in Fig. A2, where the vertical sampling in the UTLS is $3 \mathrm{~km}$ and the lowest tangent altitude reaches down to about $6 \mathrm{~km}$ at all latitudes.
Table A1. Variable CI thresholds between 10 and $25 \mathrm{~km}$ derived from Sembhi et al. (2012).

\begin{tabular}{lccc}
\hline altitude/latitudes & $0-40$ & $40-65$ & $65-90$ \\
\hline 10 & 3 & 3 & 3 \\
11 & 3 & 4 & 4 \\
12 & 4 & 5 & 5 \\
13 & 5 & 5 & 5 \\
14 & 5 & 5 & 5 \\
15 & 5 & 5 & 5 \\
16 & 5 & 5 & 5 \\
17 & 5 & 5 & 5 \\
18 & 5 & 5 & 5 \\
19 & 5 & 5 & 5 \\
20 & 6 & 5 & 4 \\
21 & 6 & 5 & 4 \\
22 & 6 & 5 & 3 \\
23 & 6 & 5 & 3 \\
24 & 6 & 5 & 2 \\
25 & 6 & 5 & 2 \\
\hline
\end{tabular}

\section{A3 Simulated and measured profiles}

In the following representative simulated and measured profiles for clear air, ice clouds, and aerosol are shown in order to illustrate the behaviour of the CI, AI, and ACI and to discuss their differences.

The simulated clear air profiles for the $\mathrm{CI}$ and $\mathrm{AI}$ (Fig. A3a) show an altitude dependence for the CI and the AI. In the simulations the $\mathrm{CI}$ is getting slightly smaller between 20 and about $12 \mathrm{~km}$ altitude whereas the $\mathrm{AI}$ is getting larger. Below $12 \mathrm{~km}$ altitude the CI and the AI are getting significantly smaller with descending altitude. At altitudes below $20 \mathrm{~km}$ the ACI (Fig. A3b) is the AI. The benefit of using the ACI instead of the CI is that above about $10 \mathrm{~km}$ the ACI is not getting smaller with decreasing altitude. This allows for a larger and altitude- and latitude-independent threshold value, making this index more sensitive towards thin aerosol layers.

Comparing the clear air simulations (Fig. A3) with MIPAS measurements (Fig. A4) shows a good agreement of the shape of the vertical profile but systematically larger values for the simulated CI and ACI above about $10 \mathrm{~km}$ (polar atmosphere: Fig. A4a, tropics: Fig. A4b, c). This difference is due to the fact that in the clear air simulations no aerosol is considered, but in the real atmosphere a variable amount of (background) aerosol is always present and hence the index values are expected to be smaller. This effect is more pronounced for the ACI than for the CI, because the $960 \mathrm{~cm}^{-1}$ window used for the ACI is only sensitive to the target species aerosol, whereas the $832 \mathrm{~cm}^{-1}$ window used for the $\mathrm{CI}$ is in addition slightly affected by the water vapour continuum and some other trace gases. Below about $10 \mathrm{~km}$ in the tropics the simulations of the CI and ACI show systematically smaller index values than the measurements (Fig. A4c). 
(a) MIPAS cloud index orbit 4950818082011 15:05-16:45 UTC

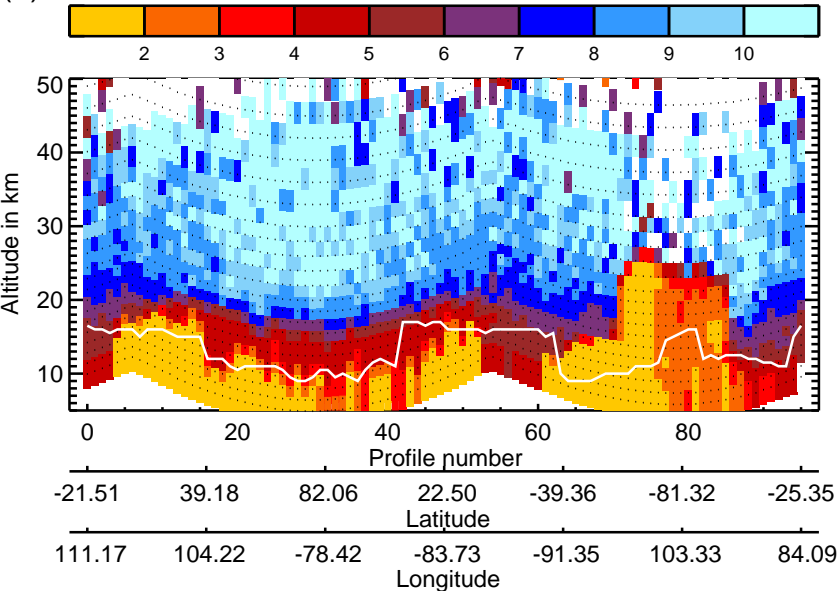

(b) MIPAS aerosol index orbit 4950818082011 15:05-16:45 UTC
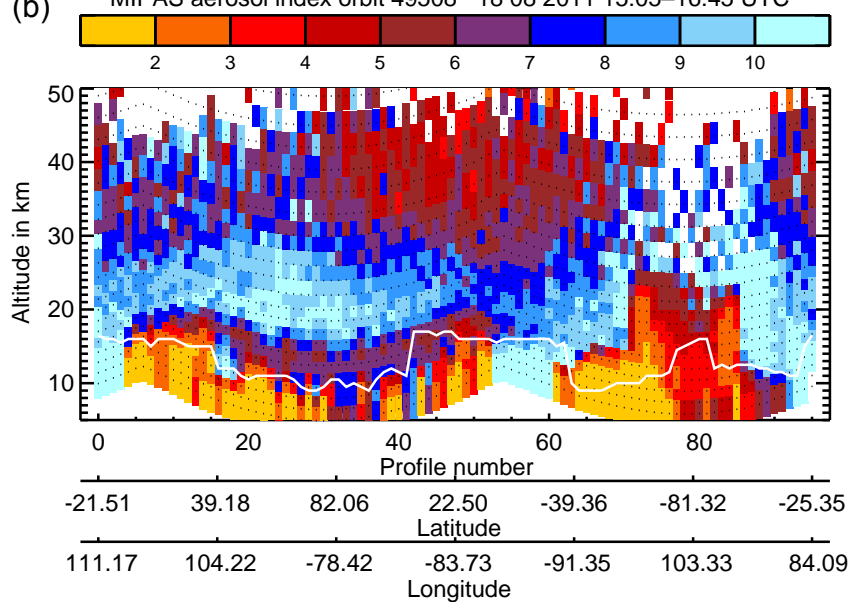

(c) MIPAS cloud + aerosol index orbit 49508 18082011 15:05-16:45 UTC

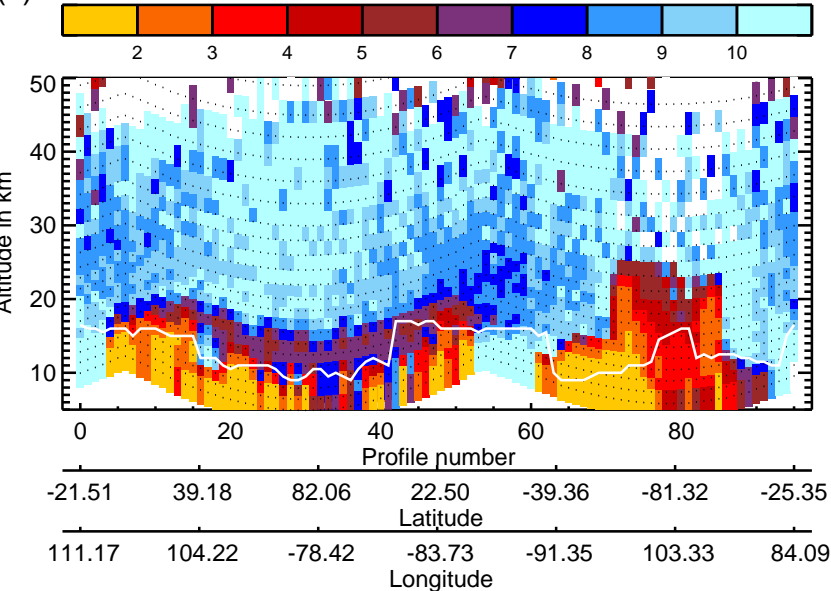

Figure A1. CI (a), AI (b), and ACI (c) up to $50 \mathrm{~km}$ altitude for MIPAS orbit 49508 measured on 18 August 2011.

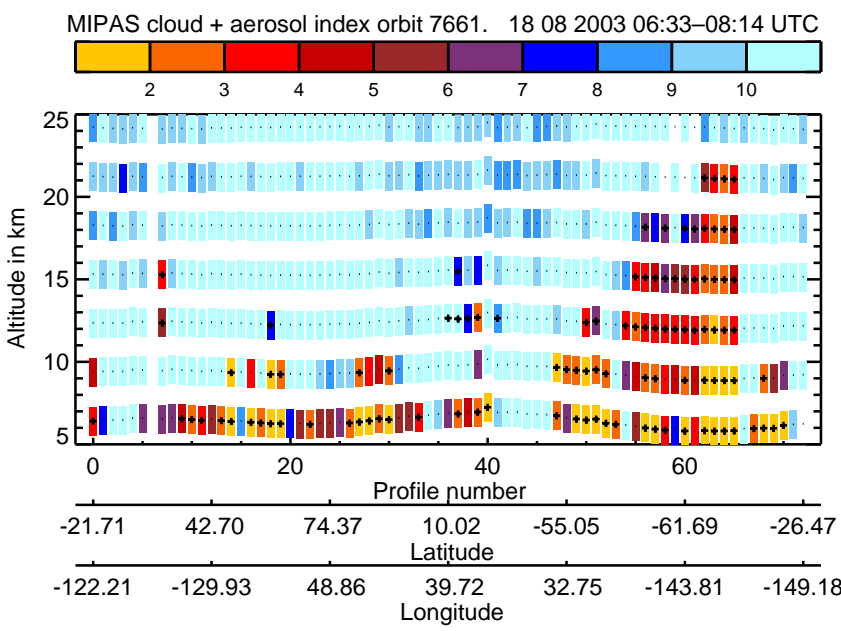

Figure A2. ACI profiles for MIPAS orbit 7661 measured on $18 \mathrm{Au}-$ gust 2003 . The black crossed denote cloudy regions identified by a fixed CI threshold of 2 below $10 \mathrm{~km}$ and by the variable thresholds above $10 \mathrm{~km}$ (Sembhi et al., 2012).

Certainly the climatological data used in the simulations do not represent the atmospheric state perfectly, but sensitivity tests showed that the ACI simulations below $7.5 \mathrm{~km}$ at high and midlatitudes and $9.5 \mathrm{~km}$ in the tropics are affected by the water vapour continuum. The water vapour scheme used in JURASSIC is the MT_CKD scheme (Clough et al., 2005) that is known to have a limited accuracy at the lowest altitudes (Sect. 3.1). However, for the aerosol detection and ice filtering method presented here this issue has no further implications, because the simulated clear air spectra with low ACI values fall in the ice cloud group and hence will also be filtered out.

Simulated profiles of the CI, AI, and ACI for a $1 \mathrm{~km}$ thick ice cloud, volcanic ash, and sulfate aerosol are presented in Figs. A5 to A7. For the three particle types the deviation from the clear air profile is more pronounced for the AI than for the $\mathrm{CI}$. The $\mathrm{CI}$ and $\mathrm{AI}$ minimum values due to the cloud layer are located slightly below cloud altitude. For ice clouds (Fig. A5) the $\mathrm{AI}$ is systematically larger than the CI, whereas for volcanic ash (Fig. A6) and sulfate aerosol (Fig. A7) the AI can be smaller than the CI or both values are similar. This is due to the spectral slope of the extinction coefficient, where the extinction at 960 is larger than at 830 for sulfate aerosol and ash and equal or smaller for ice. The simulations demonstrate that the AI is highly sensitive not only to ice and aerosol but to aerosol in particular.

\section{A4 Separation between ice clouds and non-ice PSCs}

In Fig. 5d we show an example for PSCs where measurements fall above the separation lines. On that particular day the polar vortex was shifted towards about $60^{\circ} \mathrm{N}$ over Siberia (e.g. see MLS data at http://mls.jpl.nasa.gov/) and temperatures were below $196 \mathrm{~K}$ and above $188 \mathrm{~K}$ so that STS and 

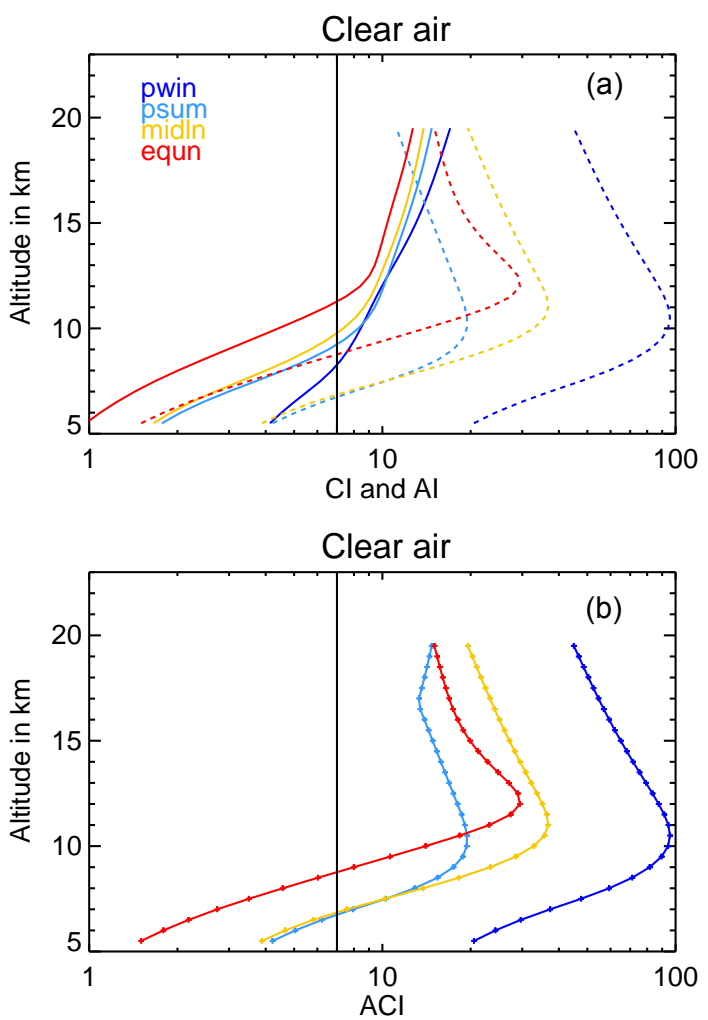

Figure A3. Simulated profiles for clear air in polar winter (dark blue), summer (light blue), midlatitude (yellow), and equatorial (red) atmosphere. (a) CI (solid lines) and AI (dashed lines). (b) ACI.

NAT PSCs can exist but not ice. Figure A8a shows the location and altitudes of MIPAS particle detections that fall in the non-ice group. Most of these detections are located in the polar region. As in Fig. 5 d, but for $0-60^{\circ} \mathrm{N}$, Fig. A8b shows that the measurements above the separation lines disappear, except for a few PSC detections south of $60^{\circ} \mathrm{N}$ over Siberia and some aerosol in the tropics. The fact that the BTD correlation used here for filtering out ice clouds also improves the discrimination between ice and non-ice PSCs has been investigated in a separate study by Spang et al. (2016).
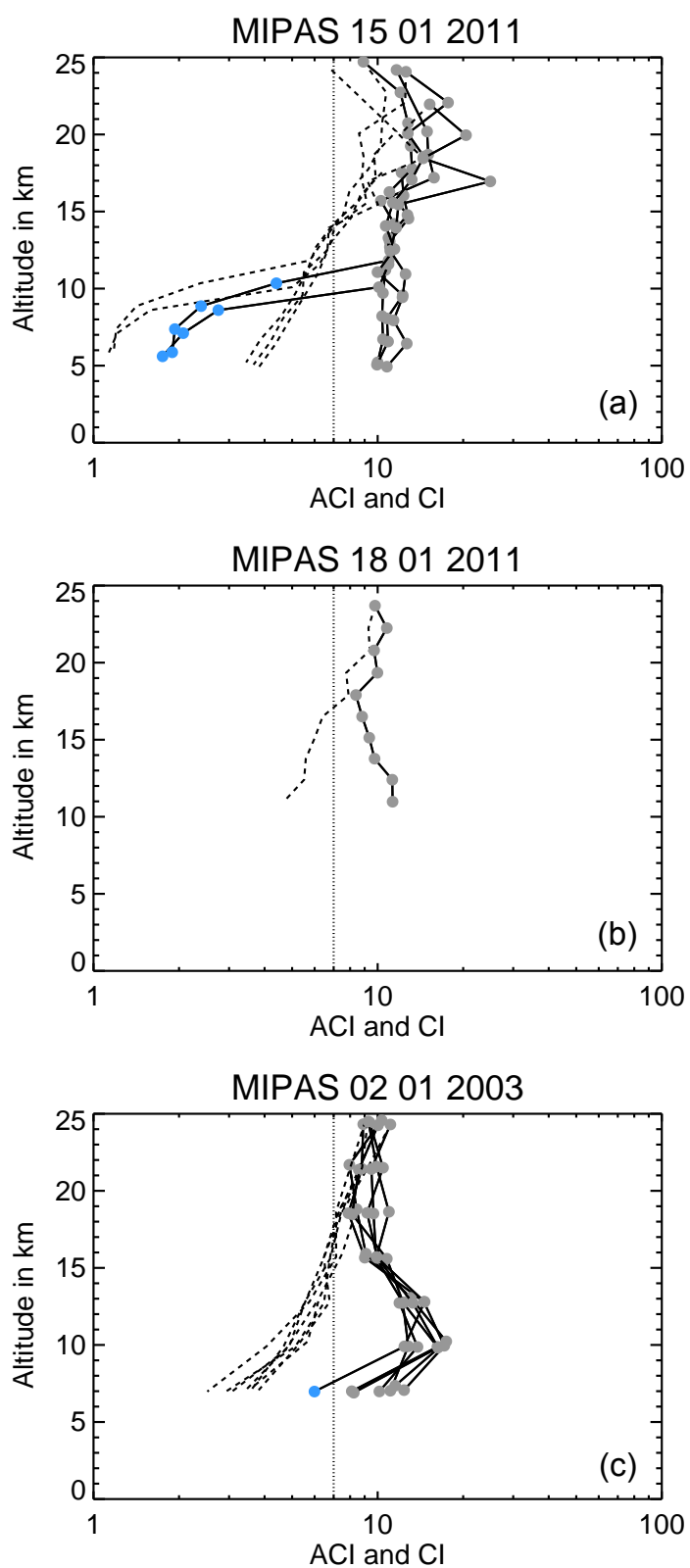

Figure A4. Measured ACI (solid lines) and CI (dashed lines) profiles for (a) polar winter $2011\left(70-90^{\circ} \mathrm{N}, 0-2.5^{\circ} \mathrm{E}\right)$, (b) tropics $2011\left(0-30^{\circ} \mathrm{S}, 110-120^{\circ} \mathrm{E}\right)$, and (c) tropics $2003\left(0-20^{\circ} \mathrm{N}, 30\right.$ $\left.60^{\circ} \mathrm{E}\right)$. Grey dots indicate clear air spectra and blue dots indicate spectra affected by ice clouds according to the method presented in Sect. 3.2. 

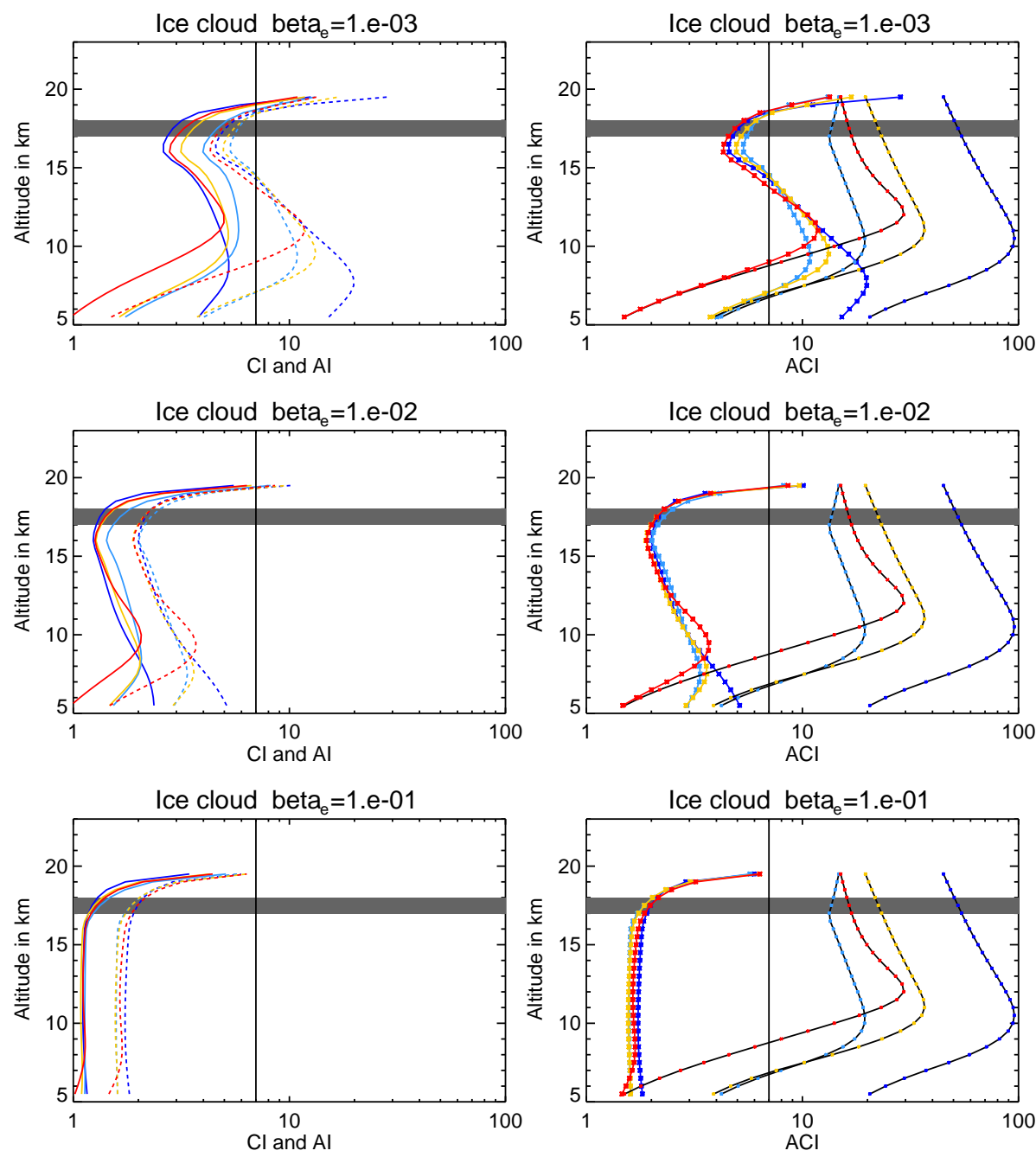

Figure A5. Simulated profiles for a $1 \mathrm{~km}$ thick ice cloud for three extinctions and the mode radius of $24 \mu \mathrm{m}$. Left column: CI (solid lines) and AI (dashed lines). Right column ACI for cloud (coloured lines) and clear air (black lines). The grey area indicates the cloud layer. The colours indicate the atmosphere type: blue - polar winter; light blue - polar summer; yellow - midlatitude; red - tropical atmosphere. 

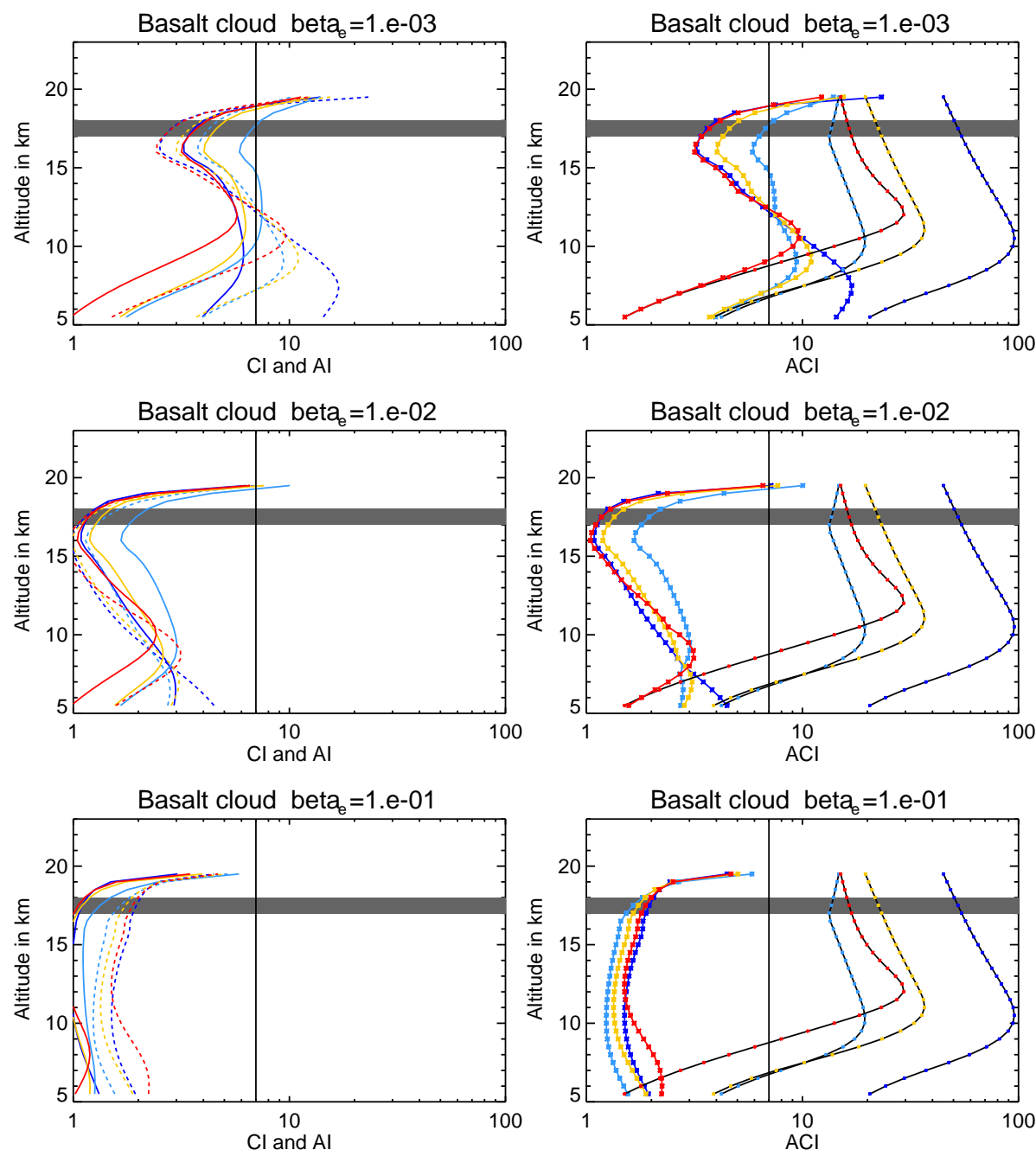

Figure A6. Same as Fig. A5 but for volcanic ash and the mode radius of $0.8 \mu \mathrm{m}$. 

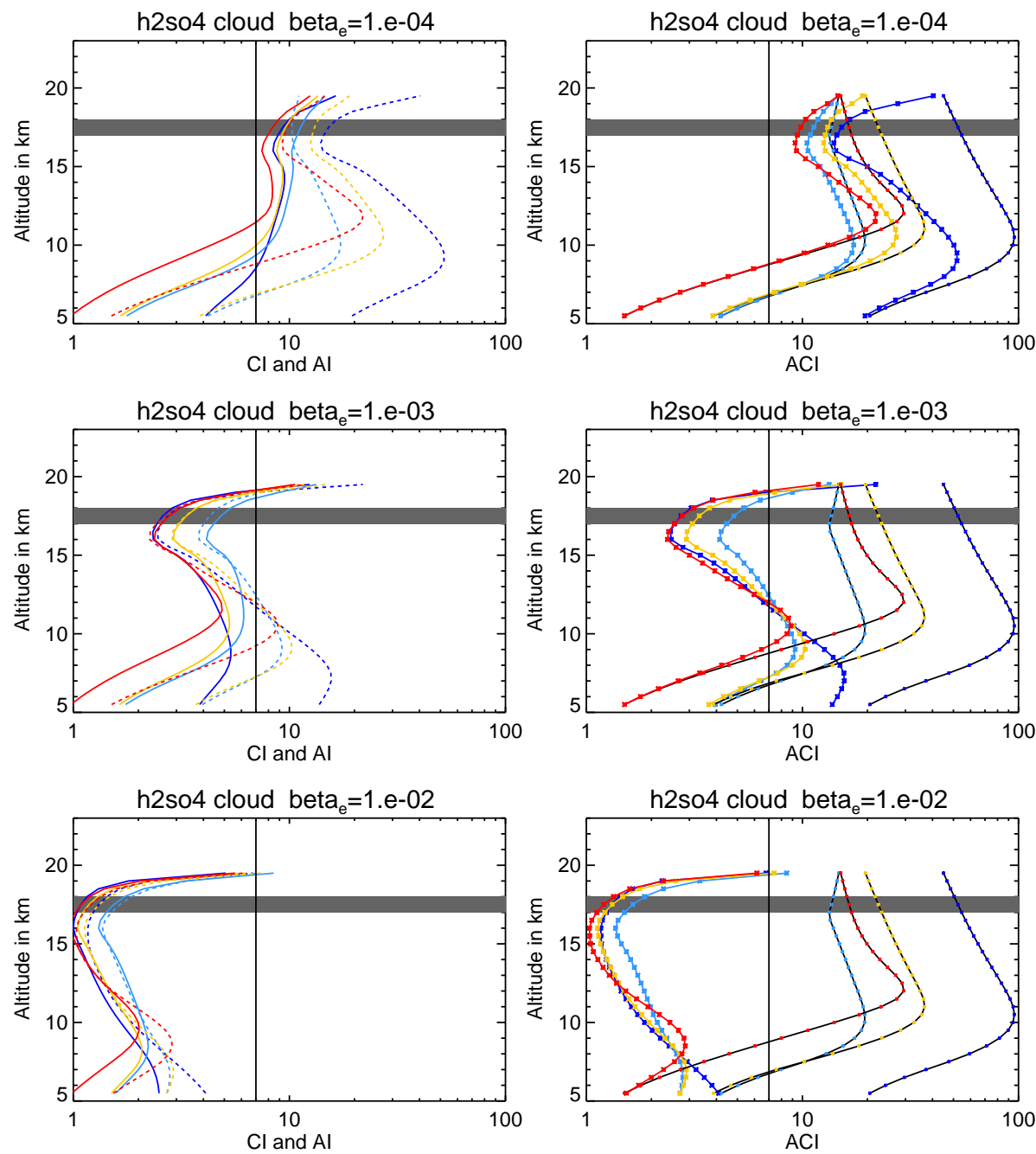

Figure A7. Same as Fig. A5 but for sulfate aerosol and the mode radius of $0.6 \mu \mathrm{m}$.
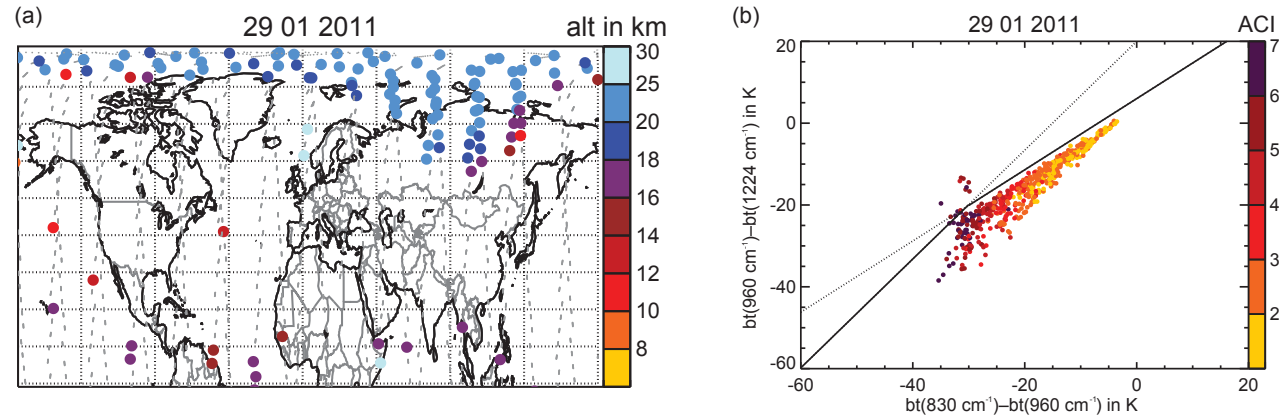

Figure A8. Detection of non-ice particles on 29 January 2011. (a) Location and altitudes of the particle detections. (b) Same as Fig. 5d but for $0-60^{\circ} \mathrm{N}$. 
Acknowledgements. We thank one anonymous reviewer for helpful comments and Mike Fromm for his critical and constructive review. We are grateful to Thomas Kirchartz for discussions and comments on the manuscript. We also thank W. Lahoz for a grammatical and stylistic revision of the manuscript. The MIPAS data were provided by the European Space Agency. The AIRS data were obtained from the NASA Goddard Earth Sciences Data Information and Services Center (GES DISC). The simulations were performed on JuRoPA at Forschungszentrum Jülich. We gratefully acknowledge the computing time granted on the supercomputer at Jülich Supercomputing Centre (JSC).

The article processing charges for this open-access publication were covered by a Research

Centre of the Helmholtz Association.

Edited by: E. Kyrölä

Reviewed by: two anonymous referees

\section{References}

Ackerman, S. A.: Remote sensing aerosols using satellite infrared observations, J. Geophys. Res., 102, 17069-17079, doi:10.1029/96JD03066, 1997.

Ackerman, S. A., Smith, W. L., Spinhirne, J. D., and Revercomb, H. E.: The 27-28 October 1986 FIRE IFO cirrus case-study - spectral properties of cirrus clouds in the $8-12 \mu \mathrm{m}$ window, Mon. Weather Rev., 118, 2377-2388, doi:10.1175/15200493(1990)118<2377:TOFICC >2.0.CO;2, 1990.

Aumann, H., Chahine, M., Gautier, C., Goldberg, M., Kalnay, E., McMillin, L., Revercomb, H., Rosenkranz, P., Smith, W., Staelin, D., Strow, L., and Susskind, J.: AIRS/AMSU/HSB on the Aqua mission: Design, science objectives, data products, and processing systems, IEEE Trans. Geosci. Remote Sens., 41, 253-264, doi:10.1109/TGRS.2002.808356, 2003.

Baran, A., Foot, J., and Dibben, P.: Satellite detection of volcanic sulfuric-acid aerosol, Geophys. Res. Lett., 20, 1799-1801, doi:10.1029/93GL01965, 1993.

Bauman, J. J., Russell, P. B., Geller, M. A., and Hamill, P.: A stratospheric aerosol climatology from SAGE II and CLAES measurements: 2. Results and comparisons, 1984-1999, J. Geophys. Res., 108, 4383, doi:10.1029/2002JD002993, 2003.

Bourassa, A. E., Robock, A., Randel, W. J., Deshler, T., Rieger, L. A., Lloyd, N. D., Llewellyn, E. J. T., and Degenstein, D. A.: Large Volcanic Aerosol Load in the Stratosphere Linked to Asian Monsoon Transport, Science, 337, 78-81, doi:10.1126/science.1219371, 2012.

Casadevall, T.: The 1989-1990 eruption of Redoubt volcano, Alaska - impacts on aircraft operations, J. Volc. Geotherm. Res., 62, 301-316, doi:10.1016/0377-0273(94)90038-8, 1994.

Clarisse, L., Hurtmans, D., Prata, A. J., Karagulian, F., Clerbaux, C., De Maziere, M., and Coheur, P.-F.: Retrieving radius, concentration, optical depth, and mass of different types of aerosols from high-resolution infrared nadir spectra, Appl. Optics, 49, 37133722,2010

Clarisse, L., Coheur, P.-F., Prata, F., Hadji-Lazaro, J., Hurtmans, D., and Clerbaux, C.: A unified approach to infrared aerosol remote sensing and type specification, Atmos. Chem. Phys., 13, 2195 2221, doi:10.5194/acp-13-2195-2013, 2013.

Clough, S., Shephard, M. W., Mlawer, E. J., Delamere, J. S., Iacono, M. J., Cady-Pereira, K., Boukabara, S., and Brown, P. D.: Atmospheric radiative transfer modeling: A summary of the AER codes, J. Quant. Spectrosc. Ra., 91, 233-244, 2005.

de Reus, M., Borrmann, S., Bansemer, A., Heymsfield, A. J., Weigel, R., Schiller, C., Mitev, V., Frey, W., Kunkel, D., Kürten, A., Curtius, J., Sitnikov, N. M., Ulanovsky, A., and Ravegnani, F.: Evidence for ice particles in the tropical stratosphere from in-situ measurements, Atmos. Chem. Phys., 9, 6775-6792, doi:10.5194/acp-9-6775-2009, 2009.

Dee, D. P., Uppala, S. M., Simmons, A. J., Berrisford, P., Poli, P., Kobayashi, S., Andrae, U., Balmaseda, M. A., Balsamo, G., Bauer, P., Bechtold, P., Beljaars, A. C. M., van de Berg, L., Bidlot, J., Bormann, N., Delsol, C., Dragani, R., Fuentes, M., Geer, A. J., Haimberger, L., Healy, S. B., Hersbach, H., Holm, E. V., Isaksen, L., Kallberg, P., Koehler, M., Matricardi, M., McNally, A. P., Monge-Sanz, B. M., Morcrette, J.-J., Park, B.-K., Peubey, C., de Rosnay, P., Tavolato, C., Thépaut, J.-N., and Vitart, F.: The ERA-Interim reanalysis: configuration and performance of the data assimilation system, Q. J. Roy. Meteor. Soc., 137, 553-597, doi:10.1002/qj.828, 2011.

Deshler, T., Peter, T., Müller, R., and Crutzen, P.: The Lifetime of Leewave-induced Ice Particles In the Arctic Stratosphere .1. Balloonborne Observations, Geophys. Res. Lett., 21, 1327-1330, 1994.

Di Pierro, M., Jaeglé, L., Eloranta, E. W., and Sharma, S.: Spatial and seasonal distribution of Arctic aerosols observed by the CALIOP satellite instrument (2006-2012), Atmos. Chem. Phys., 13, 7075-7095, doi:10.5194/acp-13-7075-2013, 2013.

Echle, G., von Clarmann, T., and Oelhaf, H.: Optical and microphysical parameters of the Mt. Pinatubo aerosol as determined from MIPAS-B mid-IR limb emission spectra, J. Geophys. Res., 103, 19193-19211, 1998.

ESA: available at: https://earth.esa.int/web/ guest/data-access/browse-data-products/-/article/ mipas-localized-calibrated-emission-spectra-1541, last access: January 2015.

Fairlie, T. D., Vernier, J.-P., Natarajan, M., and Bedka, K. M.: Dispersion of the Nabro volcanic plume and its relation to the Asian summer monsoon, Atmos. Chem. Phys., 14, 7045-7057, doi:10.5194/acp-14-7045-2014, 2014.

Fischer, H., Birk, M., Blom, C., Carli, B., Carlotti, M., von Clarmann, T., Delbouille, L., Dudhia, A., Ehhalt, D., Endemann, M., Flaud, J. M., Gessner, R., Kleinert, A., Koopman, R., Langen, J., López-Puertas, M., Mosner, P., Nett, H., Oelhaf, H., Perron, G., Remedios, J., Ridolfi, M., Stiller, G., and Zander, R.: MIPAS: an instrument for atmospheric and climate research, Atmos. Chem. Phys., 8, 2151-2188, doi:10.5194/acp-8-2151-2008, 2008.

Frey, W., Borrmann, S., Kunkel, D., Weigel, R., de Reus, M., Schlager, H., Roiger, A., Voigt, C., Hoor, P., Curtius, J., Krämer, M., Schiller, C., Volk, C. M., Homan, C. D., Fierli, F., Di Donfrancesco, G., Ulanovsky, A., Ravegnani, F., Sitnikov, N. M., Viciani, S., D'Amato, F., Shur, G. N., Belyaev, G. V., Law, K. S., and Cairo, F.: In situ measurements of tropical cloud properties in the West African Monsoon: upper tropospheric ice clouds, Mesoscale Convective System outflow, and subvisual cirrus, At- 
mos. Chem. Phys., 11, 5569-5590, doi:10.5194/acp-11-55692011, 2011

Fridlind, A. M., Ackerman, A. S., Jensen, E. J., Heymsfield, A. J., Poellot, M. R., Stevens, D. E., Wang, D. H., Miloshevich, L. M., Baumgardner, D., Lawson, R. P., Wilson, J. C., Flagan, R. C., Seinfeld, J. H., Jonsson, H. H., VanReken, T. M., Varutbangkul, V., and Rissman, T. A.: Evidence for the predominance of midtropospheric aerosols as subtropical anvil cloud nuclei, Science, 304, 718-722, 2004.

Friedl-Vallon, F., Gulde, T., Hase, F., Kleinert, A., Kulessa, T., Maucher, G., Neubert, T., Olschewski, F., Piesch, C., Preusse, P., Rongen, H., Sartorius, C., Schneider, H., Schönfeld, A., Tan, V., Bayer, N., Blank, J., Dapp, R., Ebersoldt, A., Fischer, H., Graf, F., Guggenmoser, T., Höpfner, M., Kaufmann, M., Kretschmer, E., Latzko, T., Nordmeyer, H., Oelhaf, H., Orphal, J., Riese, M., Schardt, G., Schillings, J., Sha, M. K., Suminska-Ebersoldt, O., and Ungermann, J.: Instrument concept of the imaging Fourier transform spectrometer GLORIA, Atmos. Meas. Tech., 7, 35653577, doi:10.5194/amt-7-3565-2014, 2014.

Fromm, M., Torres, O., Diner, D., Lindsey, D., Vant Hull, B., Servranckx, R., Shettle, E. P., and Li, Z.: Stratospheric impact of the Chisholm pyrocumulonimbus eruption: 1. Earthviewing satellite perspective, J. Geophys. Res., 113, d08202, doi:10.1029/2007JD009153, 2008.

Fromm, M., Lindsey, D. T., Servranckx, R., Yue, G., Trickl, T., Sica, R., Doucet, P., and Godin-Beekmann, S. E.: The untold story of pyrocumulonimbus, B. Am. Meteorol. Soc., 91, 1193-1209, doi:10.1175/2010BAMS3004.1, 2010.

Fromm, M., Kablick, III, G., Nedoluha, G., Carboni, E., Grainger, R., Campbell, J., and Lewis, J.: Correcting the record of volcanic stratospheric aerosol impact: Nabro and Sarychev Peak, J. Geophys. Res., 119, 10343-10364, doi:10.1002/2014JD021507, 2014.

Gangale, G., Prata, A. J., and Clarisse, L.: The infrared spectral signature of volcanic ash determined from high-spectral resolution satellite measurements, Remote Sens. Environ., 114, 414-425, doi:10.1016/j.rse.2009.09.007, 2010.

Gille, J., Barnett, J., Arter, P., Barker, M., Bernath, P., Boone, C., Cavanaugh, C., Chow, J., Coffey, M., Craft, J., Craig, C., Dials, M., Dean, V., Eden, T., Edwards, D. P., Francis, G., Halvorson, C., Harvey, L., Hepplewhite, C., Khosravi, R., Kinnison, D., Krinsky, C., Lambert, A., Lee, H., Lyjak, L., Loh, J., Mankin, W., Massie, S., McInerney, J., Moorhouse, J., Nardi, B., Packman, D., Randall, C., Reburn, J., Rudolf, W., Schwartz, M., Serafin, J., Stone, K., Torpy, B., Walker, K., Waterfall, A., Watkins, R., Whitney, J., Woodard, D., and Young, G.: High Resolution Dynamics Limb Sounder: Experiment overview, recovery, and validation of initial temperature data, J. Geophys. Res., 113, d16S43, doi:10.1029/2007JD008824, 2008.

Gordley, L. L. and Russell, J. M.: Rapid inversion of limb radiance data using an emissivity growth approximation, Appl. Optics, 20, 807-813, 1981.

Grainger, R. G., Lambert, A., Taylor, F. W., Remedios, J. J., Rodgers, C. D., Corney, M., and Kerridge, B. J.: Infrared-absorption by volcanic stratospheric aerosols observed by ISAMS, Geophys. Res. Lett., 20, 1283-1286, doi:10.1029/93GL00823, 1993.

Grainger, R. G., Peters, D. M., Thomas, G. E., Smith, A. J. A., Siddans, R., Carboni, E., and Dudhia, A.: Measuring Volcanic Plume and Ash Properties from Space, in: Remote-sensing of Volcanoes and Volcanic Processes: Integrating Observation and Modelling, edited by: Pyle, D., Mather, T., and Biggs, J., The Geological Society Special Publication 380, doi:10.1144/SP380.7, 2013.

Grießbach, S.: Clouds and aerosol in infrared radiative transfer calculations for the analysis of satellite observations, vol. 139 of Schriften des Forschungszentrums Jülich, Reihe Energie \& Umwelt, Forschungszentrum Jülich, Jülich, available at: http:// juwel.fz-juelich.de:8080/dspace/handle/2128/4597 (last access: 24 July 2014), 2012.

Griessbach, S., Hoffmann, L., von Hobe, M., Müller, R., Spang, R., and Riese, M.: A six-year record of volcanic ash detection with Envisat MIPAS, in: Proceedings of ESA ATMOS 2012, European Space Agency, ESA Special Publication SP-708 (CDROM), 2012.

Griessbach, S., Hoffmann, L., Hoepfner, M., Riese, M., and Spang, R.: Scattering in infrared radiative transfer: A comparison between the spectrally averaging model JURASSIC and the lineby-line model KOPRA, J. Quant. Spectrosc. Ra., 27, 102-118, doi:10.1016/j.jqsrt.2013.05.004, 2013.

Griessbach, S., Hoffmann, L., Spang, R., and Riese, M.: Volcanic ash detection with infrared limb sounding: MIPAS observations and radiative transfer simulations, Atmos. Meas. Tech., 7, 1487 1507, doi:10.5194/amt-7-1487-2014, 2014.

Grimsdell, A. W., Alexander, M. J., May, P. T., and Hoffmann, L.: Model study of waves generated by convection with direct validation via satellite, J. Atmos. Sci., 67, 1617-1631, 2010.

Guehenneux, Y., Gouhier, M., and Labazuy, P.: Improved space borne detection of volcanic ash for real-time monitoring using 3-Band method, J. Volc. Geotherm. Res., 293, 25-45, doi:10.1016/j.jvolgeores.2015.01.005, 2015.

Günther, T., Schulze, M., Friederici, A., and Theisel, H.: Visualizing Volcanic Clouds in the Atmosphere and Their Impact on Air Traffic, IEEE Computer Graphics and Applications, 36, 36-47, doi:10.1109/MCG.2015.121, 2016.

Hoffmann, L. and Alexander, M. J.: Retrieval of stratospheric temperatures from Atmospheric Infrared Sounder radiance measurements for gravity wave studies, J. Geophys. Res., 114, D07105, doi:10.1029/2008JD011241, 2009.

Hoffmann, L., Kaufmann, M., Spang, R., Müller, R., Remedios, J. J., Moore, D. P., Volk, C. M., von Clarmann, T., and Riese, M.: Envisat MIPAS measurements of CFC-11: retrieval, validation, and climatology, Atmos. Chem. Phys., 8, 3671-3688, doi:10.5194/acp-8-3671-2008, 2008.

Hoffmann, L., Weigel, K., Spang, R., Schroeder, S., Arndt, K., Lehmann, C., Kaufmann, M., Ern, M., Preusse, P., Stroh, F., and Riese, M.: CRISTA-NF measurements of water vapor during the SCOUT-O3 Tropical Aircraft Campaign, Adv. Space Res., 43, 74-81, 2009.

Hoffmann, L., Griessbach, S., and Meyer, C. I.: Volcanic emissions from AIRS observations: detection methods, case study, and statistical analysis, in: Proceedings of SPIE Volume 9242, Remote Sensing of Clouds and the Atmosphere XIX; and Optics in Atmospheric Propagation and Adaptive Systems XVII, SPIE Remote Sensing Europe, doi:10.1117/12.2066326, 2014.

Hoffmann, L., Rößler, T., Griessbach, S., Heng, Y., and Stein, O.: Lagrangian transport simulations of volcanic sulfur dioxide emissions: Impact of meteorological data products, J. Geophys Res., 121, 4651-4673, doi:10.1002/2015JD023749, 2016. 
Hong, G., Yang, P., Heidinger, A. K., Pavolonis, M. J., Baum, B. A., and Platnick, S. E.: Detecting opaque and nonopaque tropical upper tropospheric ice clouds: A trispectral technique based on the MODIS 8-12 $\mu \mathrm{m}$ window bands, J. Geophys. Res., 115, d20214, doi:10.1029/2010JD014004, 2010.

Höpfner, M., Larsen, N., Spang, R., Luo, B. P., Ma, J., Svendsen, S. H., Eckermann, S. D., Knudsen, B., Massoli, P., Cairo, F., Stiller, G., v. Clarmann, T., and Fischer, H.: MIPAS detects Antarctic stratospheric belt of NAT PSCs caused by mountain waves, Atmos. Chem. Phys., 6, 1221-1230, doi:10.5194/acp-6-1221-2006, 2006.

Höpfner, M., Pitts, M. C., and Poole, L. R.: Comparison between CALIPSO and MIPAS observations of polar stratospheric clouds, J. Geophys. Res., 114, D00H05, doi:10.1029/2009JD012114, 2009.

Höpfner, M., Glatthor, N., Grabowski, U., Kellmann, S., Kiefer, M., Linden, A., Orphal, J., Stiller, G., von Clarmann, T., Funke, B., and Boone, C. D.: Sulfur dioxide $\left(\mathrm{SO}_{2}\right)$ as observed by MIPAS/Envisat: temporal development and spatial distribution at $15-45 \mathrm{~km}$ altitude, Atmos. Chem. Phys., 13, 10405-10423, doi:10.5194/acp-13-10405-2013, 2013.

Hummel, J. R., Shettle, E. P., and Longtin, D. R.: A New Background Stratospheric Aerosol Model for Use in Atmospheric Radiation Models, AFGL-TR-88-0166, Air Force Geophysics Laboratory, Hanscom AFB, MA, 1988.

Iwasaki, S., Maruyama, K., Hayashi, M., Ogino, S.-Y., Ishimoto, H., Tachibana, Y., Shimizu, A., Matsui, I., Sugimoto, N., Yamashita, K., Saga, K., Iwamoto, K., Kamiakito, Y., Chabangborn, A., Thana, B., Hashizume, M., Koike, T., and Oki, T.: Characteristics of aerosol and cloud particle size distributions in the tropical tropopause layer measured with optical particle counter and lidar, Atmos. Chem. Phys., 7, 3507-3518, doi:10.5194/acp7-3507-2007, 2007.

Junge, C. E., Manson, J. E., and Chagnon, C. W.: A World-wide Stratospheric Aerosol Layer, Science, 133, 1478-1479, 1961.

Karagulian, F., Clarisse, L., Clerbaux, C., Prata, A. J., Hurtmans, D., and Coheur, P. F.: Detection of volcanic $\mathrm{SO}_{2}$, ash, and $\mathrm{H}_{2} \mathrm{SO}_{4}$ using the Infrared Atmospheric Sounding Interferometer (IASI), J. Geophys. Res., 115, D00L02, doi:10.1029/2009JD012786, 2010.

Kent, G., Trepte, C., Wang, P., and Lucker, P.: Problems in separating aerosol and cloud in the Stratospheric Aerosol and Gas Experiment (SAGE) II data set under conditions of lofted dust: Application to the Asian deserts, J. Geophys. Res., 108, 4410, doi:10.1029/2002JD002412, 2003.

Kleinert, A., Aubertin, G., Perron, G., Birk, M., Wagner, G., Hase, F., Nett, H., and Poulin, R.: MIPAS Level 1B algorithms overview: operational processing and characterization, Atmos. Chem. Phys., 7, 1395-1406, doi:10.5194/acp-7-13952007, 2007.

Klüser, L., Erbertseder, T., and Meyer-Arnek, J.: Observation of volcanic ash from Puyehue-Cordón Caulle with IASI, Atmos. Meas. Tech., 6, 35-46, doi:10.5194/amt-6-35-2013, 2013.

Klüser, L., Martynenko, D., and Holzer-Popp, T.: Thermal infrared remote sensing of mineral dust over land and ocean: a spectral SVD based retrieval approach for IASI, Atmos. Meas. Tech., 4, 757-773, doi:10.5194/amt-4-757-2011, 2011

Klueser, L., Kleiber, P., Holzer-Popp, T., and Grassian, V. H.: Desert dust observation from space - Application of measured min- eral component infrared extinction spectra, Atmos. Environ., 54, 419-427, doi:10.1016/j.atmosenv.2012.02.011, 2012.

Koren, I., Kaufman, Y. J., Washington, R., Todd, M. C., Rudich, Y., Martins, J. V., and Rosenfeld, D.: The Bodele depression: a single spot in the Sahara that provides most of the mineral dust to the Amazon forest, Environ. Res. Lett., 1, 014005 , doi:10.1088/1748-9326/1/1/014005, 2006.

Kremser, S., Thomason, L. W., von Hobe, M., Hermann, M., Deshler, T., Timmreck, C., Toohey, M., Stenke, A., Schwarz, J. P., Weigel, R., Fueglistaler, S., Prata, F. J., Vernier, J.-P., Schlager, H., Barnes, J. E., Antuña-Marrero, J.-C., Fairlie, D., Palm, M., Mahieu, E., Notholt, J., Rex, M., Bingen, C., Vanhellemont, F., Bourassa, A., Plane, J. M. C., Klocke, D., Carn, S. A., Clarisse, L., Trickl, T., Neely, R., James, A. D., Rieger, L., Wilson, J. C., and Meland, B.: Stratospheric aerosol - Observations, processes, and impact on climate, Rev. Geophys., 54, 278-335, doi:10.1002/2015RG000511, 2016.

Lambert, A., Grainger, R. G., Remedios, J. J., Rodgers, C. D., Corney, M., and Taylor, F. W.: Measurements of the evolution of the Mt. Pinatubo aerosol cloud by ISAMS, Geophys. Res. Lett., 20, 1287-1290, doi:10.1029/93GL00827, 1993.

Lambert, A., Grainger, R. G., Rodgers, C. D., Taylor, F. W., Mergenthaler, J. L., Kumer, J. B., and Massie, S. T.: Global evolution of the Mt Pinatubo volcanic aerosols observed by the infrared limb-sounding instruments CLAES and ISAMS on the Upper Atmosphere Research Satellite, J. Geophys. Res., 102, 1495-1512, doi:10.1029/96JD00096, 1997.

Liu, Z., Fairlie, T. D., Uno, I., Huang, J., Wu, D., Omar, A., Kar, J., Vaughan, M., Rogers, R., Winker, D., Trepte, C., Hu, Y., Sun, W., Lin, B., and Cheng, A.: Transpacific transport and evolution of the optical properties of Asian dust, J. Quant. Spectrosc. Ra., 116, 24-33, doi:10.1016/j.jqsrt.2012.11.011, 2013.

Massie, S., Gille, J., Khosravi, R., Lee, H., Kinnison, D., Francis, G., Nardi, B., Eden, T., Craig, C., Halvorson, C., Coffey, M., Packman, D., Cavanaugh, C., Craft, J., Dean, V., Ellis, D., Barnett, J., Hepplewhite, C., Lambert, A., Manney, G., Strawa, A., and Legg, M.: High Resolution Dynamics Limb Sounder observations of polar stratospheric clouds and subvisible cirrus, J. Geophys. Res., 112, d24S31, doi:10.1029/2007JD008788, 2007.

Massie, S. T., Deshler, T., Thomas, G. E., Mergenthaler, J. L., and Russell, J. M.: Evolution of the infrared properties of the Mount Pinatubo aerosol cloud over Laramie, Wyoming, J. Geophys. Res., 101, 23007-23019, 1996.

Mossop, S.: Volcanic dust collected at altitude of $20 \mathrm{~km}$, Nature, 203, 824-827, doi:10.1038/203824a0, 1964.

Murphy, D. M., Cziczo, D. J., Hudson, P. K., and Thomson, D. S.: Carbonaceous material in aerosol particles in the lower stratosphere and tropopause region, J. Geophys. Res., 112, D04203, doi:10.1029/2006JD007297, 2007.

NASA: available at: http://airs.jpl.nasa.gov/, last access: January 2015.

NASA: available at: http://www-calipso.larc.nasa.gov/products/ lidar/browse_images/show_date.php?s=production \&v= V3-01\&browse_date=2011-08-18, 2016.

Oelhaf, H., von Clarmann, T., Fischer, H., Friedl-Vallon, F., Fritzsche, C., Linden, A., Piesch, C., Seefeldner, M., and Volker, W.: Stratospheric $\mathrm{ClONO}_{2}$ and $\mathrm{HNO}_{3}$ profiles inside the Arctic vortex from MIPAS-B limb emission-spectra ob- 
tained during EASOE, Geophys. Res. Lett., 21, 1263-1266, doi:10.1029/93GL01303, 1994.

Offermann, D., Grossmann, K.-U., Barthol, P., Knieling, P., Riese, M., and Trant, R.: Cryogenic Infrared Spectrometers and Telescopes for the Atmosphere (CRISTA) experiment and middle atmosphere variability, J. Geophys. Res., 104, 16311-16325, 1999.

Penning de Vries, M. J. M., Dörner, S., Pukite, J., Hörmann, C., Fromm, M. D., and Wagner, T.: Characterisation of a stratospheric sulfate plume from the Nabro volcano using a combination of passive satellite measurements in nadir and limb geometry, Atmos. Chem. Phys., 14, 8149-8163, doi:10.5194/acp-148149-2014, 2014.

Peyridieu, S., Chédin, A., Tanré, D., Capelle, V., Pierangelo, C., Lamquin, N., and Armante, R.: Saharan dust infrared optical depth and altitude retrieved from AIRS: a focus over North Atlantic - comparison to MODIS and CALIPSO, Atmos. Chem. Phys., 10, 1953-1967, doi:10.5194/acp-10-1953-2010, 2010.

Pitts, M. C., Poole, L. R., Lambert, A., and Thomason, L. W.: An assessment of CALIOP polar stratospheric cloud composition classification, Atmos. Chem. Phys., 13, 2975-2988, doi:10.5194/acp-13-2975-2013, 2013.

Pollack, J., Toon, O., and Khare, B.: Optical properties of some terrestrial rocks and glasses, Icarus, 19, 372-389, doi:10.1016/0019-1035(73)90115-2, 1973.

Prata, A.: Observations of volcanic ash clouds in the 10-12-mu-m window using AVHRR/2 data, Int. J. Remote Sensing, 10, 751761, 1989a.

Prata, A.: Infrared radiative-transfer calculations for volcanic ash clouds, Geophys. Res. Lett., 16, 1293-1296, doi:10.1029/GL016i011p01293, 1989b.

Remedios, J. J., Leigh, R. J., Waterfall, A. M., Moore, D. P., Sembhi, H., Parkes, I., Greenhough, J., Chipperfield, M. P., and Hauglustaine, D.: MIPAS reference atmospheres and comparisons to V4.61/V4.62 MIPAS level 2 geophysical data sets, Atmos. Chem. Phys. Discuss., 7, 9973-10017, doi:10.5194/acpd-79973-2007, 2007.

Ridley, D. A., Solomon, S., Barnes, J. E., Burlakov, V. D., Deshler, T., Dolgii, S. I., Herber, A. B., Nagai, T., Neely, III, R. R., Nevzorov, A. V., Ritter, C., Sakai, T., Santer, B. D., Sato, M., Schmidt, A., Uchino, O., and Vernier, J. P.: Total volcanic stratospheric aerosol optical depths and implications for global climate change, Geophys. Res. Lett., 41, 7763-7769, doi:10.1002/2014GL061541, 2014.

Rieger, L. A., Bourassa, A. E., and Degenstein, D. A.: Merging the OSIRIS and SAGE II stratospheric aerosol records, J. Geophys. Res., 120, 8890-8904, doi:10.1002/2015JD023133, 2015.

Riese, M., Spang, R., Preusse, P., Ern, M., Jarisch, M., Offermann, D., and Grossmann, K. U.: Cryogenic Infrared Spectrometers and Telescopes for the Atmosphere (CRISTA) data processing and atmospheric temperature and trace gas retrieval, J. Geophys. Res., 104, 16349-16367, 1999.

Riese, M., Oelhaf, H., Preusse, P., Blank, J., Ern, M., Friedl-Vallon, F., Fischer, H., Guggenmoser, T., Höpfner, M., Hoor, P., Kaufmann, M., Orphal, J., Plöger, F., Spang, R., Suminska-Ebersoldt, O., Ungermann, J., Vogel, B., and Woiwode, W.: Gimballed Limb Observer for Radiance Imaging of the Atmosphere (GLORIA) scientific objectives, Atmos. Meas. Tech., 7, 1915-1928, doi:10.5194/amt-7-1915-2014, 2014.
Roberts, R. E., Selby, J. E. A., and Biberman, L. M.: Infrared continuum absorption by atmospheric water vapor in the 8-12- $\mu \mathrm{m}$ window, Appl. Optics, 15, 2085-2090, doi:10.1364/AO.15.002085, 1976.

Rose, W., Gu, Y., Watson, I., Yu, T., Blut, G., Prata, A., Krueger, A., Krotkov, N., Carn, S., Fromm, M., Hunton, D., Ernst, G., Viggiano, A., Miller, T., Ballenthin, J., Reeves, J., Wilson, J., Anderson, B., and Flittner, D.: The February-March 2000 Eruption of Hekla, Iceland from a Satellite Perspective, American Geophysical Union, doi:10.1029/139GM07, 107-132, 2013.

Santer, B. D., Bonfils, C., Painter, J. F., Zelinka, M. D., Mears, C., Solomon, S., Schmidt, G. A., Fyfe, J. C., Cole, J. N. S., Nazarenko, L., Taylor, K. E., and Wentz, F. J.: Volcanic contribution to decadal changes in tropospheric temperature, Nat. Geosci., 7, 185-189, doi:10.1038/NGEO2098, 2014.

Sembhi, H., Remedios, J., Trent, T., Moore, D. P., Spang, R., Massie, S., and Vernier, J.-P.: MIPAS detection of cloud and aerosol particle occurrence in the UTLS with comparison to HIRDLS and CALIOP, Atmos. Meas. Tech., 5, 2537-2553, doi:10.5194/amt-5-2537-2012, 2012.

Smithsonian Global Volcanism Programme, available at: http:// www.volcano.si.edu/, last access: 10 March 2016.

Spang, R. and Remedios, J. J.: Observations of a distinctive infrared spectral feature in the atmospheric spectra of polar stratospheric clouds measured by the CRISTA instrument, Geophys. Res. Lett., 30, 1875, doi:10.1029/2003GL017231, 2003.

Spang, R., Riese, M., and Offermann, D.: CRISTA-2 observations of the south polar vortex in winter 1997: A new dataset for polar process studies, Geophys. Res. Lett., 28, 3159-3162, doi:10.1029/2000GL012374, 2001

Spang, R., Remedios, J. J., and Barkley, M. P.: Colour indices for the detection and differentiation of cloud type in infra-red limb emission spectra, Adv. Space Res., 33, 1041-1047, 2004.

Spang, R., Remedios, J. J., Tilmes, S., and Riese, M.: MIPAS observation of polar stratospheric clouds in the Arctic 2002/2003 and Antarctic 2003 winters, in: Atmospheric remote sensing: Earth's surface, troposphere, stratosphere and mesosphere - I, edited by Burrows, J. P. and Eichmann, K. U., Adv. Space Res., 36, 868878, doi:10.1016/j.asr.2005.03.092, 2005.

Spang, R., Hoffmann, L., Kullmann, A., Olschewski, F., Preusse, P., Knieling, P., Schroeder, S., Stroh, F., Weigel, K., and Riese, M.: High resolution limb observations of clouds by the CRISTANF experiment during the SCOUT-O3 tropical aircraft campaign, Adv. Space Res., 42, 1765-1775, doi:10.1016/j.asr.2007.09.036, 2008.

Spang, R., Arndt, K., Dudhia, A., Höpfner, M., Hoffmann, L., Hurley, J., Grainger, R. G., Griessbach, S., Poulsen, C., Remedios, J. J., Riese, M., Sembhi, H., Siddans, R., Waterfall, A., and Zehner, C.: Fast cloud parameter retrievals of MIPAS/Envisat, Atmos. Chem. Phys., 12, 7135-7164, doi:10.5194/acp-12-71352012, 2012.

Spang, R., Günther, G., Riese, M., Hoffmann, L., Müller, R., and Griessbach, S.: Satellite observations of cirrus clouds in the Northern Hemisphere lowermost stratosphere, Atmos. Chem. Phys., 15, 927-950, doi:10.5194/acp-15-927-2015, 2015.

Spang, R., Hoffmann, L., Höpfner, M., Griessbach, S., Müller, R., Pitts, M. C., Orr, A. M. W., and Riese, M.: A multi-wavelength classification method for polar stratospheric cloud types us- 
ing infrared limb spectra, Atmos. Meas. Tech., 9, 3619-3639, doi:10.5194/amt-9-3619-2016, 2016.

Thomason, L., Poole, L., and Deshler, T.: A global climatology of stratospheric aerosol surface area density deduced from stratospheric aerosol and gas experiment II measurements: 1984-1994, J. Geophys. Res., 102, 8967-8976, doi:10.1029/96JD02962, 1997.

Thomason, L. W.: Toward a combined SAGE II-HALOE aerosol climatology: an evaluation of HALOE version 19 stratospheric aerosol extinction coefficient observations, Atmos. Chem. Phys., 12, 8177-8188, doi:10.5194/acp-12-8177-2012, 2012.

Thomason, L. W. and Vernier, J.-P.: Improved SAGE II cloud/aerosol categorization and observations of the Asian tropopause aerosol layer: 1989-2005, Atmos. Chem. Phys., 13, 4605-4616, doi:10.5194/acp-13-4605-2013, 2013.

Timofeyev, Y. M., Kostsov, V., and Grassl, H.: Numerical investigations of the accuracy of the remote sensing of non-LTE atmosphere by space-borne spectral measurements of limb i.r. radiation: $15 \mu \mathrm{m} \mathrm{CO} 2$ bands, $9.6 \mu \mathrm{m} \mathrm{O}_{3}$ bands and $10 \mu \mathrm{m} \mathrm{CO}_{2}$ laser bands, J. Quant. Spectrosc. Ra., 53, 613-632, doi:10.1016/00224073(95)00025-G, 1995.

Ungermann, J., Kaufmann, M., Hoffmann, L., Preusse, P., Oelhaf, H., Friedl-Vallon, F., and Riese, M.: Towards a 3-D tomographic retrieval for the air-borne limb-imager GLORIA, Atmos. Meas. Tech., 3, 1647-1665, doi:10.5194/amt-3-1647-2010, 2010.

Vernier, J. P., Thomason, L. W., Pommereau, J. P., Bourassa, A., Pelon, J., Garnier, A., Hauchecorne, A., Blanot, L., Trepte, C., Degenstein, D., and Vargas, F.: Major influence of tropical volcanic eruptions on the stratospheric aerosol layer during the last decade, Geophys. Res. Lett., 38, L12807, doi:10.1029/2011GL047563, 2011.

Volz, F. E.: Infrared optical constants of ammonium sulfate, Sahara dust, volcanic pumice and fly ash, Appl. Optics, 12, 564-568, 1973.

von Glasow, R., Bobrowski, N., and Kern, C.: The effects of volcanic eruptions on atmospheric chemistry, Chem. Geol., 263, 131-142, doi:10.1016/j.chemgeo.2008.08.020, 2009.
Warren, S. G. and Brandt, R. E.: Optical constants of ice from the ultraviolet to the microwave: A revised compilation, J. Geophys Res., 113, D14220, doi:10.1029/2007JD009744, 2008.

Weigel, K., Riese, M., Hoffmann, L., Hoefer, S., Kalicinsky, C., Knieling, P., Olschewski, F., Preusse, P., Spang, R., Stroh, F., and Volk, C. M.: CRISTA-NF measurements during the AMMASCOUT-O3 aircraft campaign, Atmos. Meas. Tech., 3, 14371455, doi:10.5194/amt-3-1437-2010, 2010.

Weigel, R., Volk, C. M., Kandler, K., Hösen, E., Günther, G., Vogel, B., Grooß, J.-U., Khaykin, S., Belyaev, G. V., and Borrmann, S.: Enhancements of the refractory submicron aerosol fraction in the Arctic polar vortex: feature or exception?, Atmos. Chem. Phys., 14, 12319-12342, doi:10.5194/acp-14-12319-2014, 2014.

Woiwode, W., Oelhaf, H., Gulde, T., Piesch, C., Maucher, G., Ebersoldt, A., Keim, C., Höpfner, M., Khaykin, S., Ravegnani, F., Ulanovsky, A. E., Volk, C. M., Hösen, E., Dörnbrack, A., Ungermann, J., Kalicinsky, C., and Orphal, J.: MIPAS-STR measurements in the Arctic UTLS in winter/spring 2010: instrument characterization, retrieval and validation, Atmos. Meas. Tech., 5, 1205-1228, doi:10.5194/amt-5-1205-2012, 2012.

Yu, F. Q., Luo, G., Bates, T. S., Anderson, B., Clarke, A., Kapustin, V., Yantosca, R. M., Wang, Y. X., and Wu, S. L.: Spatial distributions of particle number concentrations in the global troposphere: Simulations, observations, and implications for nucleation mechanisms, J. Geophys. Res., 115, D17205, doi:10.1029/2009JD013473, 2010.

Yuan, T., Remer, L. A., and Yu, H.: Microphysical, macrophysical and radiative signatures of volcanic aerosols in trade wind cumulus observed by the A-Train, Atmos. Chem. Phys., 11, 71197132, doi:10.5194/acp-11-7119-2011, 2011.

Zängl, G. and Hoinka, K.: The tropopause in the polar regions, J. Climate, 14, 3117-3139, doi:10.1175/15200442(2001)014<3117:TTITPR>2.0.CO;2, 2001. 